\title{
Intense space storms: Critical issues and open disputes
}

\author{
I. A. Daglis, ${ }^{1}$ J. U. Kozyra, ${ }^{2}$ Y. Kamide, ${ }^{3}$ D. Vassiliadis, ${ }^{4}$ A. S. Sharma,${ }^{5}$ M. W. Liemohn, ${ }^{2}$ \\ W. D. Gonzalez, ${ }^{6}$ B. T. Tsurutani, ${ }^{7}$ and G. $\mathrm{Lu}^{8}$
}

Received 4 October 2002; revised 16 January 2003; accepted 11 March 2003; published 23 May 2003.

[1] This paper addresses the question of particular characteristics and causes of intense space storms. We focus on several unresolved issues, which are critical to storm research and often nourish open disputes: the extent of interplanetary driving, the role of substorms in storm dynamics through the acceleration of particles to ring current energies, the identity of the lead agent of fast ring current decay right after storm maximum and the cause of the two-phase recovery of intense storms, the global morphology of the stormtime ring current, and the predictability of intense storms. Space storm physics has been driven by several more or less successful paradigms during the four decades following the dawn of the space flight era. However, recent suggestions and conclusions resulting from a number of observational and modeling studies have brought significant constraints to several of these paradigms. Thus for example, interplanetary driving through southward oriented magnetic fields is not always by itself sufficient to drive intense space storms because it is conditioned by internal magnetospheric conditions, the MLT distribution of storm-time magnetic disturbances is often asymmetric during the storm main phase, and charge exchange is not the lead agent of ring current decay at all times. INDEX TERMS: 2788 Magnetospheric Physics: Storms and substorms; 2778 Magnetospheric Physics: Ring current; 2784 Magnetospheric Physics: Solar wind/magnetosphere interactions; 2736 Magnetospheric Physics: Magnetosphere/ionosphere interactions; 2720 Magnetospheric Physics: Energetic particles, trapped; KEYWORDS: space storms, ring current, particle acceleration, energetic oxygen, storm recovery, storm-substorm relation

Citation: Daglis, I. A., J. U. Kozyra, Y. Kamide, D. Vassiliadis, A. S. Sharma, M. W. Liemohn, W. D. Gonzalez, B. T. Tsurutani, and G. Lu, Intense space storms: Critical issues and open disputes, J. Geophys. Res., 108(A5), 1208, doi:10.1029/2002JA009722, 2003.

\section{Introduction}

[2] Space storms are central to space weather; they interconnect in a uniquely global manner the Sun and the Earth. Space storms produce a number of distinct physical effects in near-Earth space environment: acceleration of charged particles in space, intensification of electric currents in space and on the ground, impressive aurora displays, and global magnetic disturbances on the Earth's surface, a defining storm feature and the origin of the classical name "magnetic storm", coined by Alexander von Humboldt long before the space flight era [von Humboldt, 1808].

\footnotetext{
${ }^{1}$ Institute for Space Applications and Remote Sensing, National Observatory of Athens, Penteli, Athens, Greece.

${ }^{2}$ Space Physics Research Laboratory, University of Michigan, Ann Arbor, Michigan, USA.

${ }^{3}$ Solar-Terrestrial Environment Laboratory, Nagoya University, Toyokawa, Japan.

${ }^{4}$ USRA at NASA Goddard Space Flight Center, Greenbelt, Maryland, USA.

${ }^{5}$ University of Maryland, College Park, Maryland, USA.

${ }^{6}$ Instituto de Pesquisas Espaciais, Sao Jose dos Campos, Sao Paulo, Brazil.

${ }^{7}$ Jet Propulsion Laboratory, Pasadena, California, USA.

${ }^{8}$ High-Altitude Observatory, NCAR, Boulder, Colorado, USA.

Copyright 2003 by the American Geophysical Union. 0148-0227/03/2002JA009722
}

[3] In our investigation we have used two particular intense storms, which occurred in June 1991 and September 1998 (that is, at solar maximum and rising solar cycle, respectively). This choice is motivated by the possibility of discovering solar cycle dependent characteristics of intense space storms, which becomes evident in, for example, ion composition features and effects.

[4] This paper is the third of a series of storm-dynamics reviews, preceded by Gonzalez et al. [1994] and Kamide et al. [1998b]. The first paper [Gonzalez et al., 1994] aimed to summarize the existing knowledge on space storms. The paper included a basic discussion of storm morphology, storm monitoring (Dst index), and storm development (importance of substorm ion injections). Its main focus, however, was the role of the interplanetary medium in the origin of storms. The cause and the importance of prolonged southward components of the interplanetary magnetic field $\left(\mathrm{IMF} \mathrm{B}_{s}\right.$ ) were presented in detail. The second paper [Kamide et al., 1998b] elaborated on the various types of solar wind conditions that may lead to space storms; it reviewed a number of techniques employed in the prediction of space storms, and it discussed in more detail the storm-substorm dispute, namely the indications pro and contra the ability of magnetospheric substorms to drive the storm-time ring current.

[5] The present paper focuses on particularly intense space storms and uses combined modeling and observation- 
al techniques to assess the exclusivity of solar wind forcing, the role of substorms in storm development, the relative importance of convective drift loss and charge exchange in storm recovery, and the improvement of storm predictions through the use of nonlinear dynamical techniques. Modeling of storm-associated processes and its interplay with observations has become a particularly critical and decisive research tool. During the last decade, numerous and fruitful efforts have been spent in the development of models aiming to achieve new insights in storm dynamics. An incomplete list of important contributions includes modeling studies of particle acceleration [Jordanova et al., 1994; Delcourt, 2002], magnetospheric configuration and particle transport [Liemohn et al., 2001], ring current decay [Jordanova et al., 1996; Kozyra et al., 1997], global energy balance [Kozyra et al., 2002], and relative efficiency of convection and induced electric fields in building up the ring current [Chen et al., 1994; Fok et al., 1996, 1999]. The use of electric fields in modeling is particularly critical because of the peculiarities of electric fields in the inner magnetosphere, as was shown by [Wygant et al., 1998]. We will discuss in detail particular aspects of storm modeling in the following sections.

\section{Substorms: Their Role in Storm Initiation and Buildup}

[6] An unresolved issue in storm dynamics is the role of substorms, especially in intense storms. There have been numerous studies either proposing or opposing the view that substorms play an active role in the ring current buildup. Sydney Chapman and Syun-Ichi Akasofu thought of substorms as being the key elements of a magnetic storm and thus named them "sub-storms" to suggest this idea [Akasofu and Chapman, 1961; Chapman, 1962]. In this picture, substorms have the role of magnetic pumps, each of which inflate the inner magnetosphere with hot plasma: during substorm expansion, induction electric fields accelerate magnetospheric particles and inject them into the inner magnetosphere, where they become trapped and ultimately form the ring current. According to the classic ChapmanAkasofu substorm paradigm, magnetic storms occur when successively occurring substorms deliver hot plasma to the inner magnetosphere faster than it can be dissipated.

[7] Recently, [Daglis et al., 2000] noted that the contribution of substorm injections to the ring current growth depends on the drift paths, open or closed, of the injected particles in the inner magnetosphere and their eventual trapping or escape. The transport paths depend on a number of factors, like the initial energy and pitch angles of the particles, the region (local time) of their injection, the magnetic field configuration, the site and intensity of induced electric fields at substorm onset, the excitation of waves, etc. It is obvious that a wide array of possible degrees of influence may exist and that single point spacecraft measurements just provide us parts of the puzzle. Valuable tools in this context are global images of the ring current decay product, namely images compiled through measurements of energetic neutral atoms currently performed by the IMAGE spacecraft. A couple of published storm investigations [Mitchell et al., 2001; Pollock et al., 2001] has confirmed the potential of this technique, which had been anticipated long ago by many relevant studies [e.g., Roelof, 1989; Williams et al., 1992; Daglis and Livi, 1995].

[8] Compositional variations are another important aspect of substorm influence on storm dynamics, as pointed out by [Daglis et al., 1998]. Substorm reconfigurations, with intense induced electric fields preferentially accelerating $\mathrm{O}^{+}$ions [e.g., Delcourt, 2002], lead to an increasing abundance of $\mathrm{O}^{+}$in the inner magnetosphere, which can influence ring current dynamics and storm evolution in a number of ways [Daglis et al., 1999].

[9] Here we examine the effects of substorms on the ring current during two storms, using a particular ground magnetogram technique first discussed by [Zaitzev and Boström, 1971] and [Clauer and McPherron, 1974]. As outlined by [Daglis, 2001], substorms influence storm dynamics through two coupled but distinct effects of their occurrence: the ring current growth and the Dst profile variations. Although the two effects are often considered identical, they are not. Substorms inject particles over a wide range of energies (from $<10 \mathrm{keV}$ to $>100 \mathrm{keV}$ ) into the inner magnetosphere. These particles enhance the kinetic energy density for shorter or longer time intervals, depending on their residence time in the inner magnetosphere. At the same time the magnetic variation of the near-Earth magnetotail associated with substorms affects the magnetic field recorded on the ground. Strong dipolarizations, especially in the substorm current wedge footprint, lead to enhancements of the auroral electrojets. During growth phase the intensification of the tail current increases the southward perturbation on the ground. Hence substorms can modify the geomagnetic variations at midlatitude observatories not only through their contribution to the growth of the ring current but also through their effects on the tail current and on electrojet intensity.

[10] In order to examine the spatial and temporal development of the ring current and discern the substorm effects, we calculate the azimuthal profile of the magnetic disturbance at midlatitudes using data from a large number of ground magnetic observatories. The basic technique is discussed by [Clauer and McPherron, 1974]; here we give a brief summary. We compile measurements of the axial component as a function of universal time and local time, H(t; LT), measured at a number of ground magnetometers (for this study we have used 15 magnetometers). The axial component is the projection of the horizontal field on the magnetic dipole direction. At time $t$ the azimuthal profile of the disturbed field is calculated by Fourier interpolation:

$$
\hat{H}(L T)=\sum_{i=0}^{3} A_{i} \cos (L T)+\sum_{i=1}^{3} B_{i} \sin (L T)
$$

[11] The maximum number of harmonics (3) is limited by the local-time distribution of the magnetometer stations. The coefficients $\left(\mathrm{A}_{i}, \mathrm{~B}_{i}\right)$ for a given order $\mathrm{i}$ represent qualitatively the field intensity due to currents with the symmetry of that order. Thus $A_{0}$ is representative of the symmetric ring current effect; $A_{1}$ and $B_{1}$ mainly of the asymmetric ring current effect (and possibly the effect of the current wedge, especially for large substorms); and higher orders represent rather qualitatively the effects of 


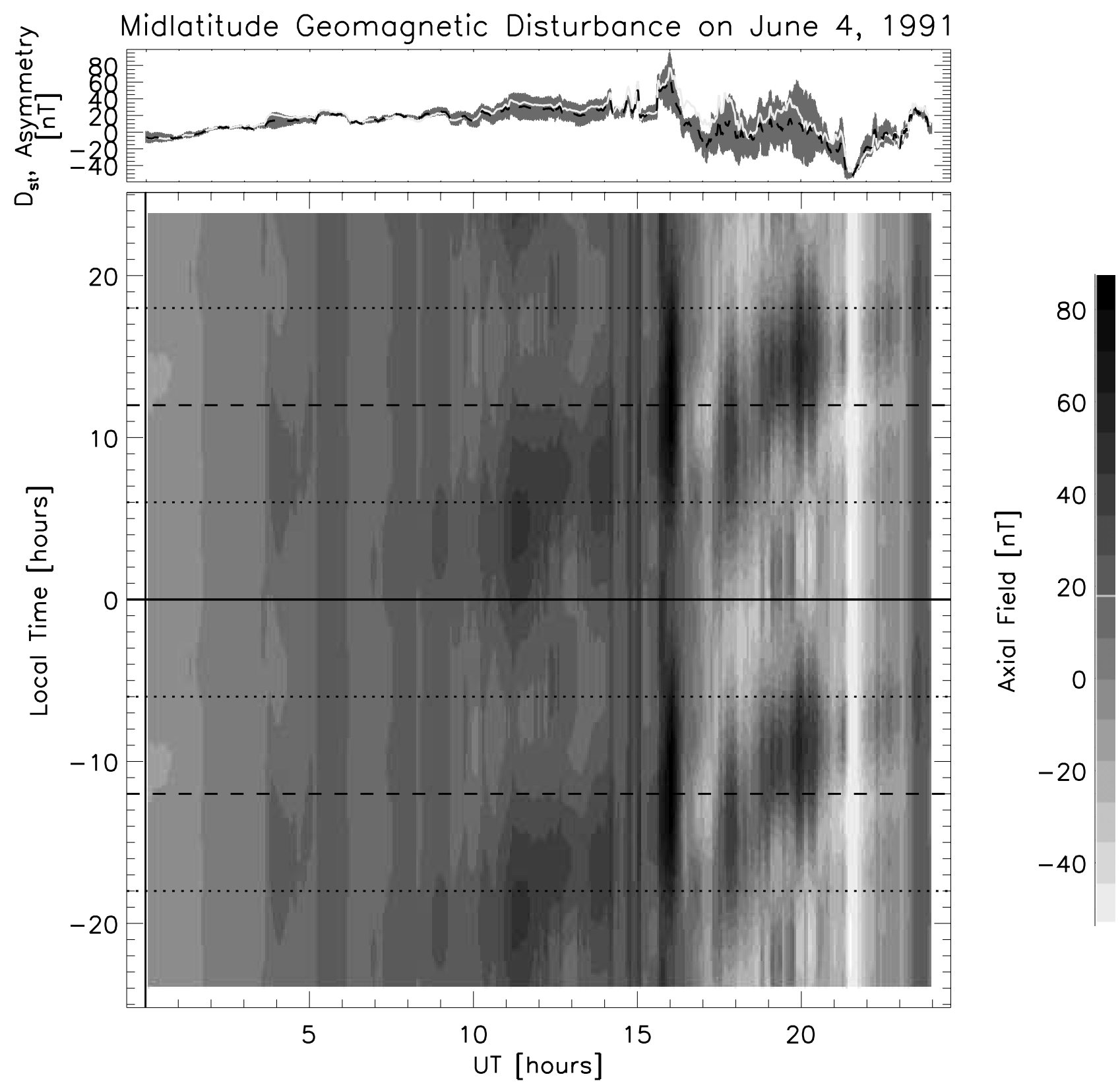

Figure 1. UT-LT map showing the azimuthal (LT) variation of the midlatitude geomagnetic disturbance on 4 June 1991. On top of the map, we have added the Dst index, calculated from the magnetometer data (white) and reconstructed from the LT-UT plot (black). The Dst time series is superposed on the range of axial field $\mathrm{H}$ observed at any given time.

localized currents such as the substorm current wedge and magnetopause and tail currents.

[12] The temporal and spatial (azimuthal) variations of the disturbance $\mathrm{H}$ are displayed in a two-dimensional UTLT diagram. The usefulness of the UT-LT map consists of the identification of its features (the spatial location of the field disturbance) with specific current systems. The analysis can be extended to quantitatively separate the effects of substorm-induced currents and other effects. In order to separate the effect of the symmetric and partial ring currents from the substorm current wedge and from particle injections, a pattern recognition scheme should be used. We have used singular value decomposition of the $\mathrm{H}(\mathrm{t} ; \mathrm{LT})$ map to identify the magnetic effect of the ring current versus that of the substorm current wedge or the effect of individual injections.

[13] The LT-UT plot in Figure 1 shows the azimuthal (LT) variation of the midlatitude geomagnetic disturbance. The "diagonal" structure having 45 degrees of gradients is the effect of the Earth's rotation. For reference we plot the Dst index, calculated from the magnetometer data (white) and reconstructed from the LT-UT plot (black), is shown on the top. The Dst time series is superposed on the range of axial field $\mathrm{H}$ observed at any given time. At 0150 UT a slow compression is visible across all LT. The compression intensifies and becomes more localized after 1000 UT and 

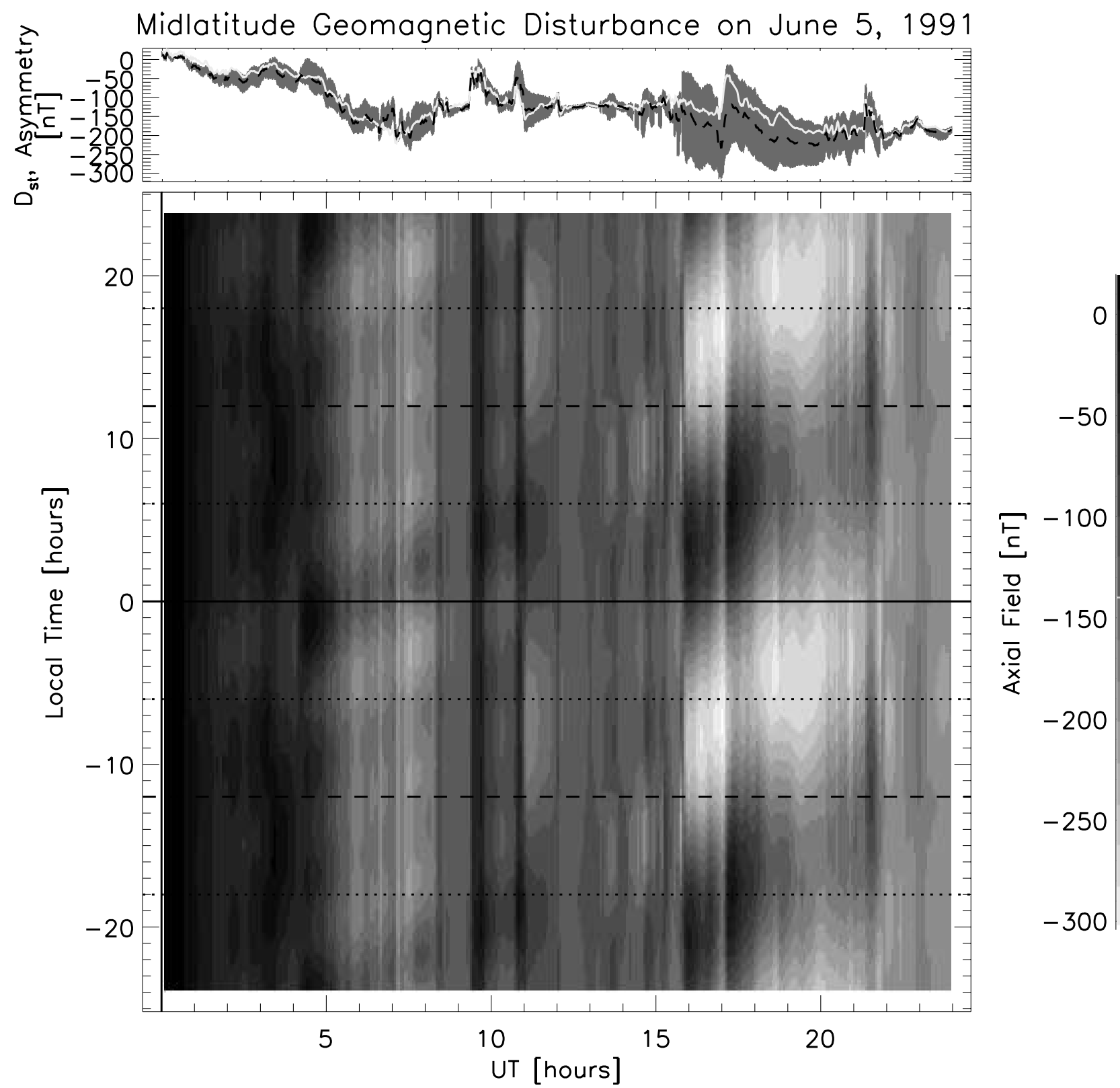

Figure 2. UT-LT map showing the azimuthal (LT) variation of the midlatitude geomagnetic disturbance on 5 June 1991.

leads to a moderate impulse at 1530 ; the compression spreads from the dayside to all local times. After the impulse is over at 1615 , the effect of magnetospheric convection sets in. It is localized first in the midnight and noon section, and gradually its magnetic signature spreads to cover the entire dusk side. The spread from midnight to dusk is due to the westward drift of the ions, which eventually carries them to the dayside. The convection signature is moderate to strong $(\Delta \mathrm{H} \sim-100 \mathrm{nT})$.

[14] The disturbance for the next day, 5 June 1991, is shown in Figure 2. The strong, dynamic azimuthal variations of the midlatitude disturbance provide qualitatively different information from the placid, simpler view of the storm afforded by Dst or even the ASYM index.

[15] The characteristic (for midlatitudes) bipolar signature of a substorm appears at 1700 UT. The positive part at midnight local time is produced by the field-aligned currents supporting the substorm current wedge, while the negative part at approximately the dusk sector and toward noon is due to the partial ring current. Note that the partial ring current part persists for several hours, while the positive field due to the substorm vanishes after 1830 UT.

[16] A characteristic pattern of convection is seen at just before 0500 UT forming the main phase of a storm with essentially all magnetometers showing a smooth depression of the magnetic field. Oscillations are seen in the main phase of the storm. Smaller features, such as sudden impulses (SIs) due to solar wind pressure increases appear clearly at several instances, e.g., at 0900, 1030, and 1400 UT. The CRRES spacecraft flew "through" the main longitude of the 1700 UT substorm and comparisons of in 

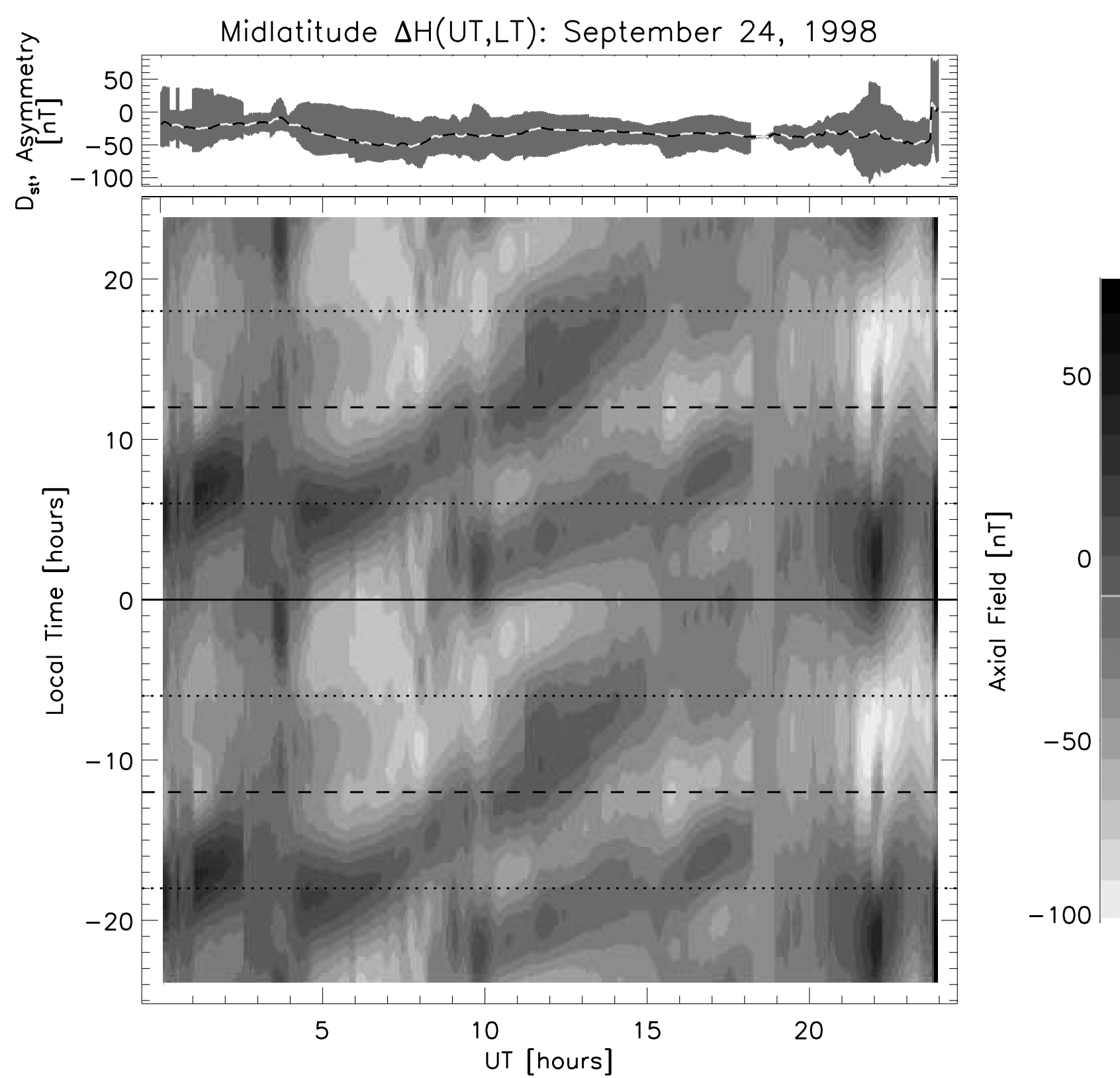

Figure 3. UT-LT map showing the azimuthal (LT) variation of the midlatitude geomagnetic disturbance on 24 September 1998.

situ ion fluxes versus total ring current estimates are given below.

[17] The next figures investigate the September 1998 storm. Figure 3 shows the midlatitude geomagnetic disturbance over the first day of the storm. A clear signature of convection enhancements is seen as the sickle-like feature on the left, starting at 0430 UT and continuing to grow until about 0830 UT. It is preceded by a sudden impulse at about 0400 UT. A weaker brief convection interval begins at 1500 UT. Large substorms at 0930 and 2200 UT punctuate the storm development. Note that within the 2200 UT substorm and after the growth phase has started at 2030 UT, a solar wind dynamic pressure hit occurs close to the onset time. The sudden change in the pressure contributes to the positive signature and in fact may have triggered the substorm.
[18] Figure 4 reflects the main phase activity of the storm on 25 September. As in Figure 2, the development in longitude and time is seen much more clearly than Dst and ASYM indices can afford to show. Note the oscillations, occurring throughout the main and recovery phases with a period of 1-2 hours. These features correlate with $A L$ and periodic increases in energetic electron fluxes and have been interpreted as substorm-related activity [Vassiliadis et al., 1999]. Alternatively, they can be associated with the sawtooth oscillations identified at geosynchronous orbit, which have been interpreted as periodic stretching and relaxation of the magnetic field as an adiabatic response at all local times [Borovsky et al., 2001].

[19] At the end of the storm (day 26 of September 1998), as the solar wind speed is decreasing, an IMF $\mathrm{B}_{s}$ distur- 

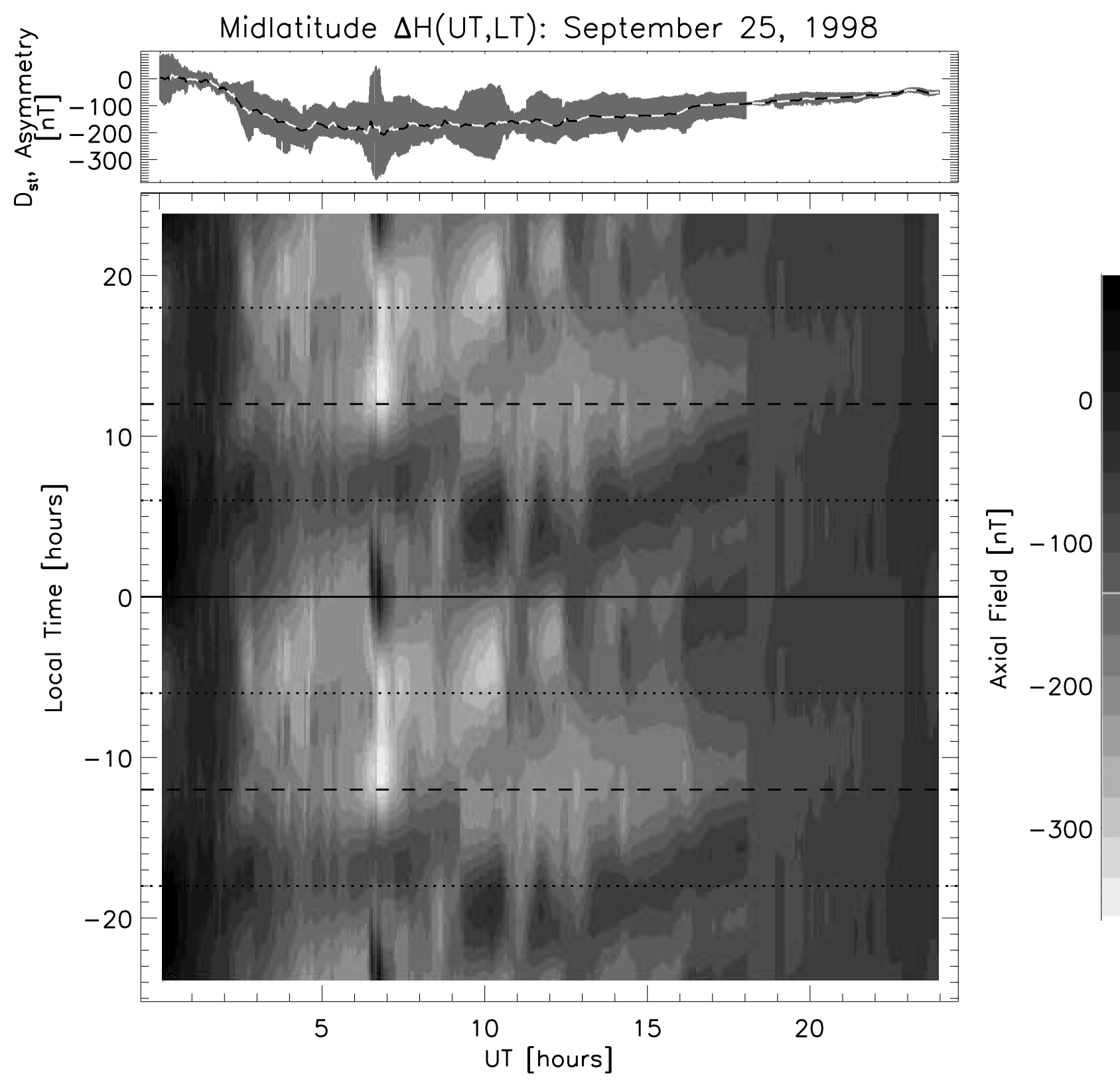

Figure 4. UT-LT map showing the azimuthal (LT) variation of the midlatitude geomagnetic disturbance on 25 September 1998.

bance creates a period of enhanced convection (0900-1300 UT). The IMF turns quickly northward at 1600 UT but still produces a moderate ring current enhancement as evidenced by the geomagnetic response (Figure 5). The ring current is somewhat asymmetric, peaking at the dusk sector $(\sim-100 \mathrm{nT})$.

\section{Storm Recovery: Looking for the Lead Agent of Fast Ring Current Destruction}

[20] The 4-6 June 1991 [Kozyra et al., 2002] and 24-27 September 1998 [Liemohn et al., 2001] magnetic storms were simulated using a kinetic ring current drift-loss model driven by dynamical fluxes at the nightside outer boundary. This Ring Current-Atmosphere Interaction Model (RAM) solves the time-dependent, gyration- and bounce-averaged kinetic equation for the phase-space distribution function $f\left(t, R, \varphi, E, \mu_{0}\right)$ of a chosen ring current species. The five independent variables are, in order, time, geocentric distance in the equatorial plane, magnetic local time, kinetic energy, and cosine of the equatorial pitch angle. The code includes collisionless drifts, energy loss and pitch-angle scattering due to Coulomb collisions with the thermal plasma, charge-exchange loss with the hydrogen geocorona, and precipitation loss to the upper atmosphere. The dynamic fluxes at the outer boundary are calculated using ion distributions observed by the LANL geosynchronous satellites [McComas et al., 1993; Belian et al., 1992] and a timevarying electric field model (in this case, McIlwain [1986]) scaled by the polar-cap potentials from the AMIE model [Richmond and Kamide, 1988] as described by [Liemohn et al., 2001]). Since the LANL spacecraft do not measure 

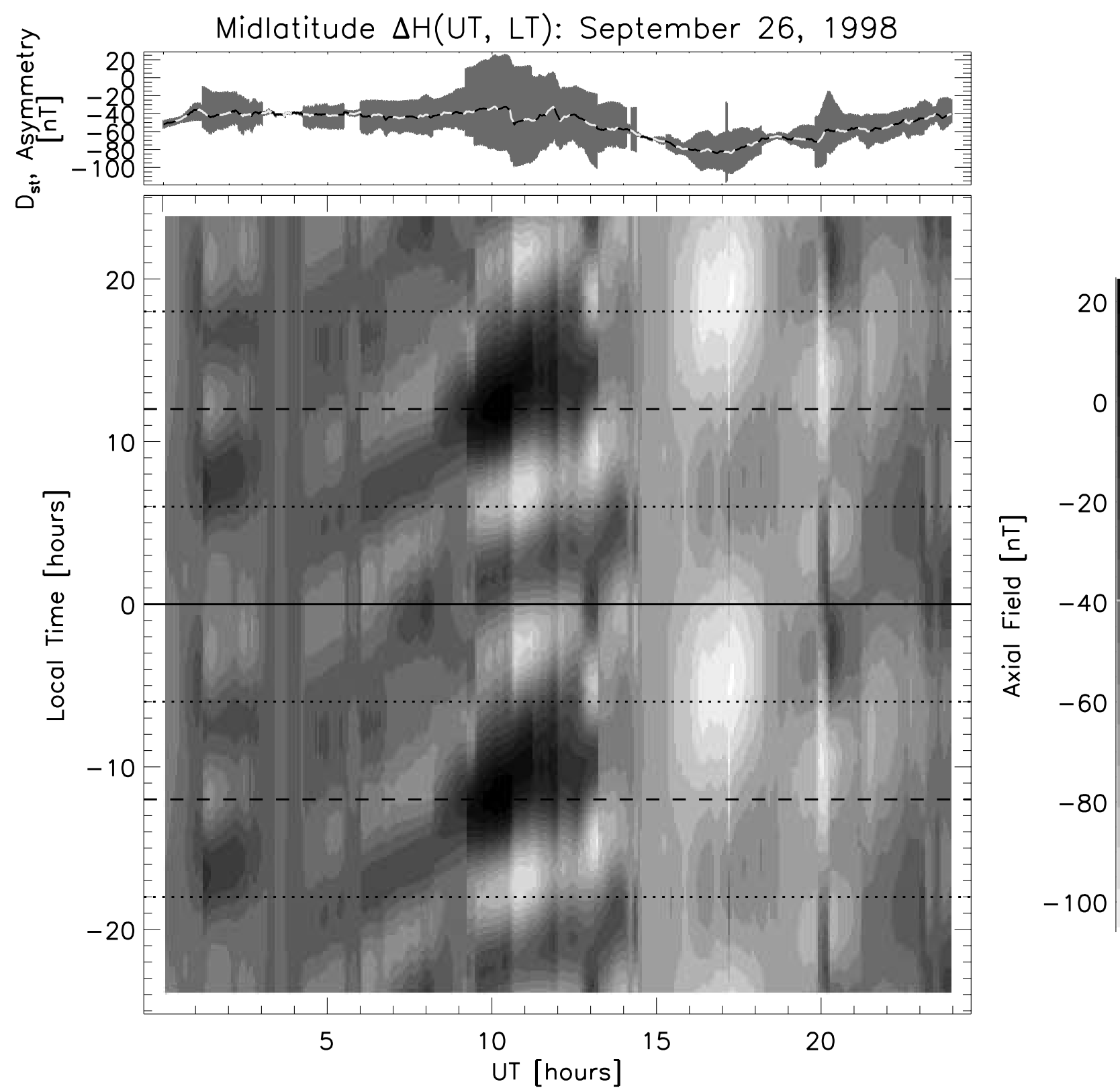

Figure 5. UT-LT map showing the azimuthal (LT) variation of the midlatitude geomagnetic disturbance on 26 September 1998.

composition, the distributions below $50 \mathrm{keV}$ are corrected for composition using a statistical relationship between $K p$, F10.7, and oxygen content derived using observations at geosynchronous orbit in the energy range below $17 \mathrm{keV} / \mathrm{e}$ [Young et al., 1982]. Above $50 \mathrm{keV} / \mathrm{e}$, the oxygen percentage is decreased exponentially with energy. The RAM model also includes a time-varying plasmasphere model developed by Rasmussen et al. [1993] and a geocoronal model from Rairden et al. [1986] for calculating realistic Coulomb and charge-exchange collisional losses.

[21] An initial condition for each storm was constructed by starting with a statistical model of the quiet-time ring current based on AMPTE/CCE observations [Sheldon and Hamilton, 1993] with a McIlwain electric field model and outer boundary distributions held constant at those observed by the LANL satellites on the day prior to the storm onset.
The model is then run to quasi-steady state, which serves as the initial condition for the magnetic storm simulation. The model and simulation results are discussed in more detail in the works by Kozyra et al. [2002] and Liemohn et al. [2001]. Here the major results are summarized and provide a global context within which relevant observations and modeling results can be interpreted.

[22] Simulation results indicate that the main phase ring current during both events was highly asymmetric (almost entirely a partial ring current) with ions making one pass through the inner magnetosphere on open drift paths. This open drift path geometry has important implications for the two-phase decay, composition changes, and multi-step development of magnetic storms. Dial plots of energy density in the equatorial plane clearly show the ring current asymmetry in Figure 6 (middle row). Observed and mod- 

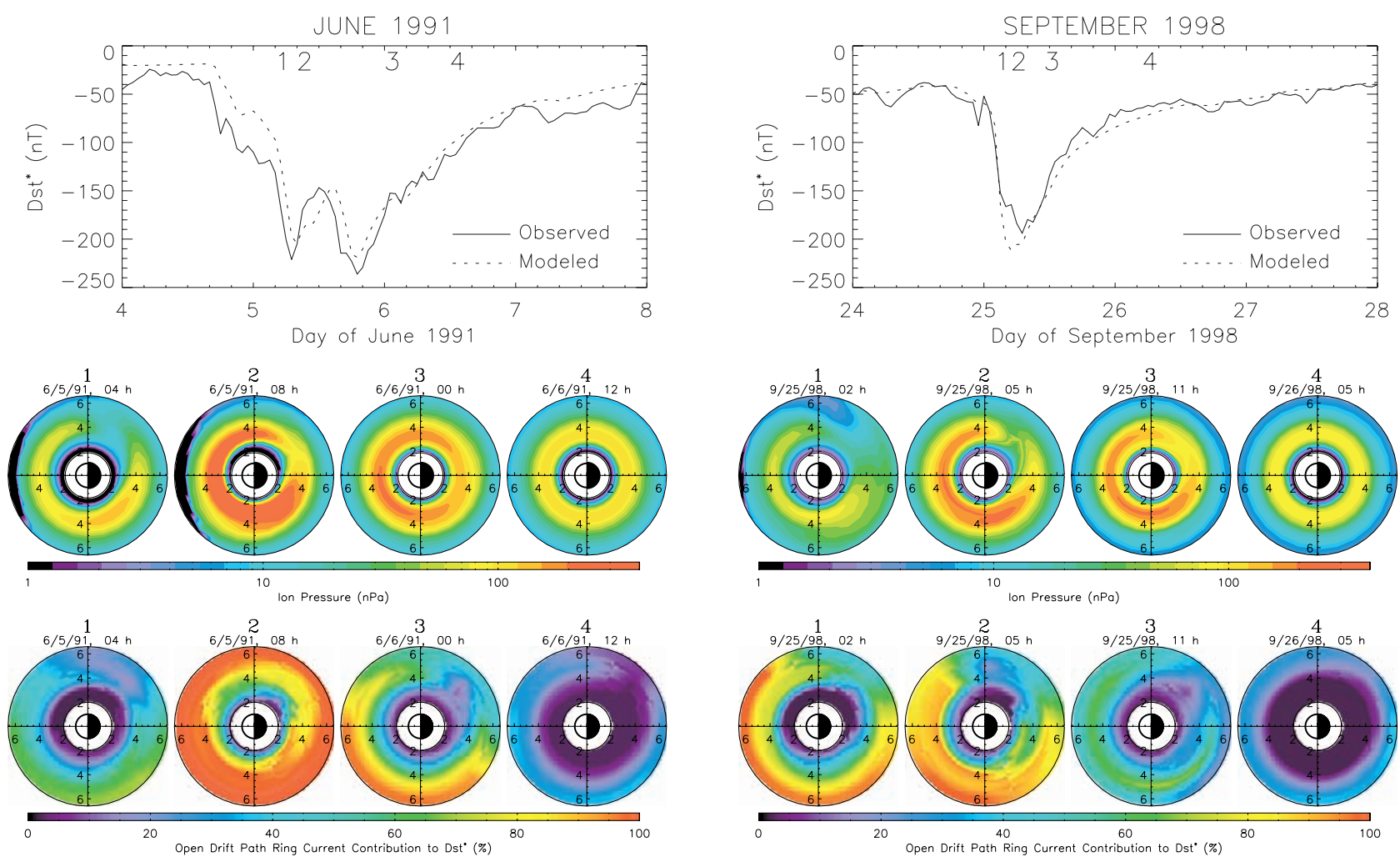

Figure 6. Results from the June 1991 (left) and September 1998 (right) magnetic storm simulations (adapted from [Kozyra et al., 2002] and [Liemohn et al., 2001]). The upper panels show the observed $D s t^{*}$ (pressure-corrected $D s t$ ) for each storm along with the model $D s t^{*}$ derived by summing the total ring current energy within the model volume according to the Dessler-Parker-Sckopke relation (see text). The ring current energy density (center) and the percent of the ring current energy on open drift paths (bottom) are plotted in the equatorial plane with noon to the left, midnight to the right, dawn at the top, and dusk at the bottom of each dial plot.

eled $D s t^{*}$ are displayed in panels at the top of the figure. The time intervals of the equatorial dial plots are indicated on these panels with respect to the $D s t^{*}$ development for each storm period. During both events the ring current transitioned from being highly asymmetric in the main phase (time intervals 1 and 2) to being progressively less asymmetric in the early recovery phase (time interval 3 ) to being weaker but symmetric in the late recovery phase (time interval 4). The ring current asymmetry is a direct consequence of the nature of the ion drift paths as they evolve. The bottom row of dial plots in Figure 6 displays the percentage of ion energy on open drift paths as a function of location in the equatorial plane. During the main phase and throughout much of the early recovery phase the convection electric field is strong, and the magnetospheric configuration allows the majority of ring current ions to move along open drift paths to the dayside magnetopause. Not until the late recovery phase are the majority of ions trapped on closed drift paths as the convection electric field weakens. Drifting along these closed paths, the ions become distributed more uniformly in local time and a symmetric ring current develops. However, by this time, the bulk of the ring current energy has already been dissipated. $\left|D s t^{*}\right|$ is at significantly less than half its maximum value by the beginning of the late recovery phase (Figure 6).

[23] A more global view of the transition between a transport-dominated and a trapped ring current is provided by Figure 7. Displayed is the percent of total ion energy on open drift paths during the two storms. This can be thought of as roughly equivalent to the percent of simulated $D s t^{*}$ contributed by ions on open drift paths. During the storm main phase, as much as $90 \%$ of the simulated $D s t^{*}$ can be due to ions on open drift paths, decreasing to less than $10 \%$ during the late recovery phase.

[24] The features of Figure 7 are consistent with observations of the two storms. CRRES observations of the June 1991 storm and estimates of charge-exchange losses, based on the CRRES data, have shown that charge exchange was the major decay process of the ring current (I. A. Daglis et al., Key features of intense space storms, submitted to Annales Geophysicae, 2003, hereinafter referred to as Daglis et al., submitted manuscript, 2003). Implicit in the analysis of the CRRES data was the assumption that the ring current was symmetric in local time and degrading dominantly due to charge-exchange. The thick line in Figure 7 (top panel) identifies the time-interval of the CRRES observations used in the analysis of Daglis et al. (submitted manuscript, 2003). It is seen that for most of the time interval of the CRRES observations more than $90 \%$ of the simulated ring current was on closed drift paths validating these assumptions. However, toward the end of the interval this percentage dropped as the recovery phase was interrupted by a small injection. The discrepancies between the distributions calculated assuming only charge exchange 

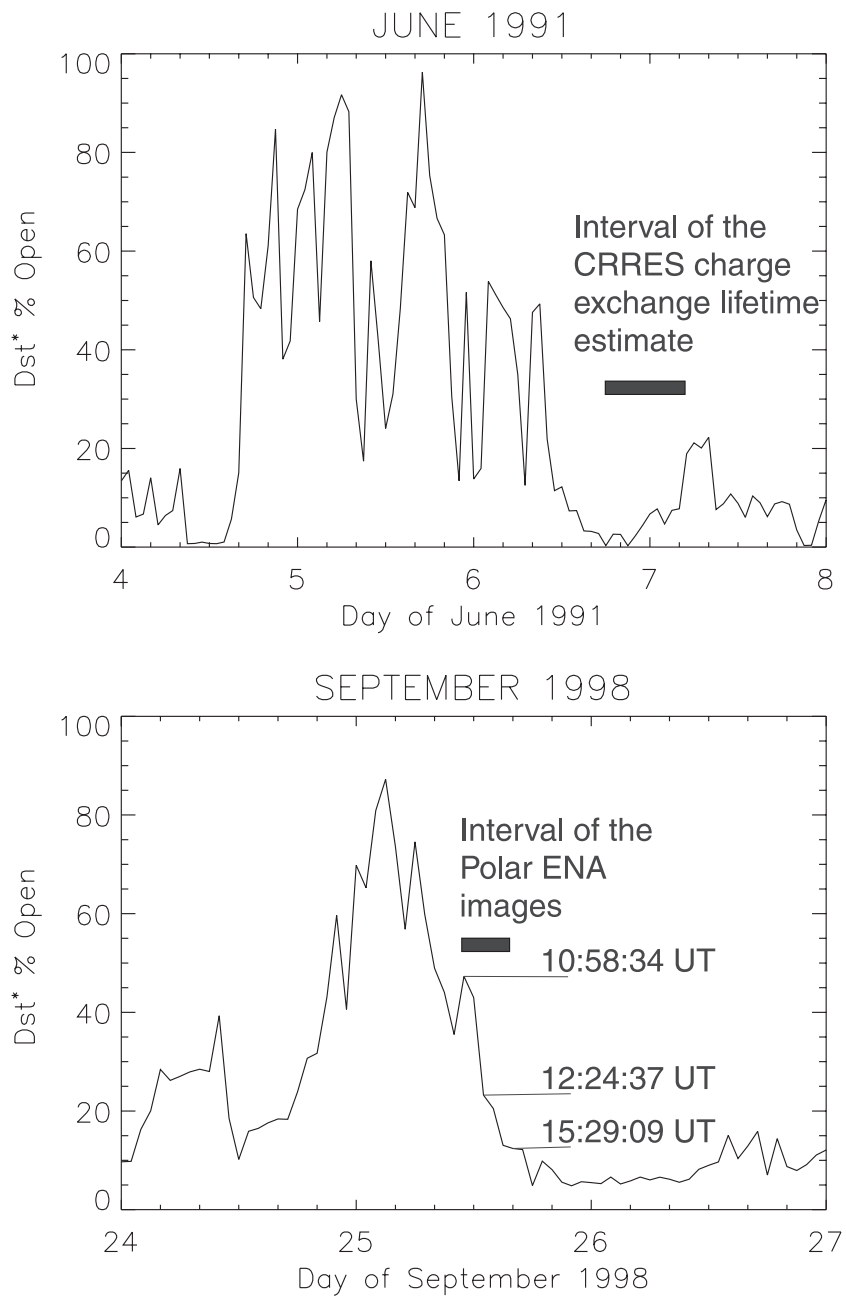

Figure 7. Percent of the total ring current energy on open drift paths for the June 1991 (upper panel) and September 1998 (lower panel) magnetic storms. In the upper panel the time interval is shown (thick line) over which charge exchange lifetimes have been estimated from CRRES observations (Daglis et al., submitted manuscript, 2003). In the lower panel a thick line is used to indicate the time of POLAR ENA observations (see text).

loss and the observed distributions may be due to the additional flow-out losses associated with the enhancement in the convection electric field during the injection.

[25] The September 1998 storm recovery was globally imaged through energetic neutral atoms by the CEPPAD/ IPS instrument on board the Polar spacecraft. Polar ENA imaging of the September 1998 storm revealed an asymmetric ring current in the main phase and in the early recovery phase, which gradually became symmetric in the late recovery phase (Daglis et al., submitted manuscript, 2003). The ENA images indicated a progressively more symmetric ring current as open drift paths are converted to closed paths in the simulation. The time interval of the imaging sequence of Polar is indicated by the thick line in the lower panel of Figure 7. At the times of the three ENA images, the percent ion energy on open drift paths in the simulation decreased from $46 \%$ to $22 \%$ and finally to $12 \%$. This is consistent with observed changes in the ratio of dusk-to-dawn ENA emissions which decreased from 4.6 to 1.8 and then to very small values (nearly symmetric) at these same times (Daglis et al., submitted manuscript, 2003).

[26] The large scale topological changes described above are important in the growth and decay of the symmetric/ partial ring current system. During the main and early recovery phases, when the ring current is topologically connected to the inner plasma sheet, changes in the plasma sheet ion distributions drive the partial ring current characteristics. Observed populations at the outer boundary move into and through the inner magnetosphere following drift paths dictated by the assumed large-scale electric field pattern (in this case a modified McIlwain [1986] field [Liemohn et al., 2001]). These plasma sheet ions are energized as they move into low $L$-values and then deenergized as the move outward toward the dayside magnetopause. During the main phase development of the ring current, ions lost at the dayside boundary are more than compensated by new particles moving in from the magnetotail; therefore Dst grows. However, as magnetic activity subsides, the electric field weakens and the plasma sheet density declines. These two events both produce a decay in the ring current/partial ring current but in different ways.

[27] Consider a weakening electric field with a constant plasma sheet density. When the electric field is strong, the topological separatrix between open and closed drift paths is formed deep within the inner magnetosphere. The weakening convection electric field drives a conversion of open to closed drift paths as the separatrix dividing these regions moves outward. If the electric field changes instantaneously to a lower value, the separatrix moves outward instantaneously. All ions are trapped and no significant change occurs in the ring current energy. However, if the electric field gradually weakens, then a part of the energetic ions are able to drift to the dayside magnetopause before they become trapped on closed drift paths. New plasma moving in on the nightside to replace these ions moves along different drift paths in the weaker electric field, penetrating less deeply with weaker adiabatic energization, and a net energy loss occurs. The amount and time scale of the energy loss and the strength of the trapped ring current during storm recovery, depend on the time scale of the electric field decrease.

[28] Now consider a decrease in the plasma sheet density with a fixed convection strength. The higher-density plasma, moving out of the dayside magnetopause on open drift paths, is gradually replaced by lower-density plasma moving through the nightside boundary. To completely replace the higher density with lower density plasma and come to a new quasi-steady-state $D s t^{*}$ value, takes a time scale on the order of the average drift time from the nightside plasma sheet to the dayside magnetopause. The actual flow-out loss time scale is a combination of time scales associated with the electric field decline and those associated with plasma sheet density changes.

[29] The conversion from the fast "flow out" losses associated with open drift paths to the slower "chargeexchange" losses associated with closed drift paths seems to 

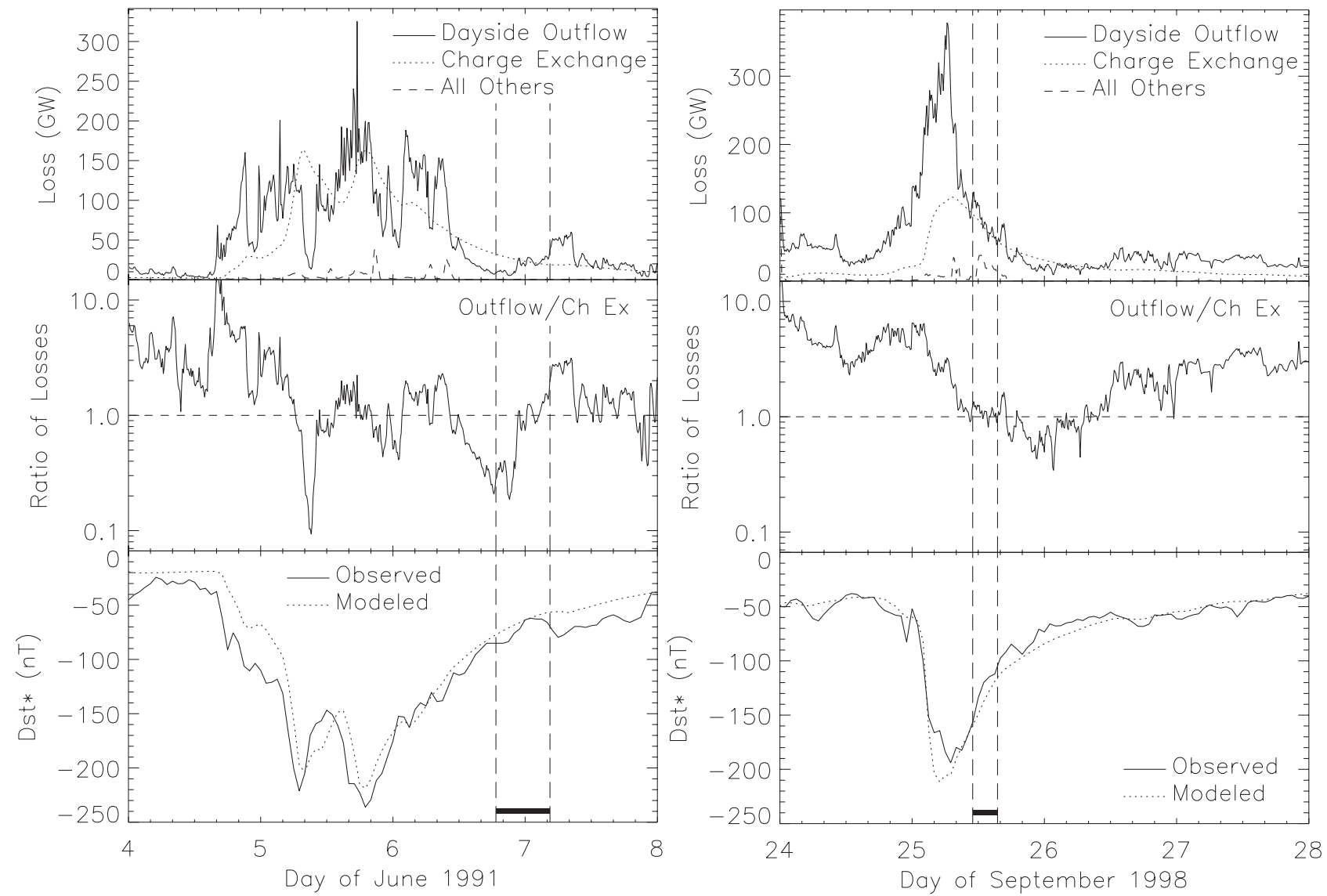

Figure 8. Summary of the major ring current losses (top panels) and their relative magnitudes (center panels) from the June 1991 (left side) and September 1998 (right side) magnetic storm simulations. A comparison of the simulated and observed $D s t^{*}$ is provided for reference in the bottom panels. The thick black lines in the bottom panels indicate the times of CRRES charge-exchange lifetime estimates (lefthand side) and POLAR ENA observations (right-hand side).

be responsible for the two-phase decay seen in the September 1998 storm. This is clearly seen in Figure 8 which displays for both storms: (1) ring current losses (top panel), (2) the ratio of outflow to charge-exchange losses (middle panel), and (3) the simulated and observed $D s t^{*}$ (bottom panel). The conversion from flow-out to charge-exchange losses is obvious in the case of the September 1998 storm (right-hand side of Figure 8). During the main phase, flowout exceeds charge-exchange loss by a factor of 5-10 (middle panel). The flow-out loss increases dramatically during the storm main phase and until storm maximum, to decrease, in an equally dramatic manner, just after storm maximum. Consequently, the early recovery phase sees a gradual increase in the importance of charge exchange until late in the early recovery phase, when charge exchange and flow-out loss are comparable (ratio of 1.0). By the end of the interval, the ring current is flowing largely on closed drift paths and charge exchange loss begins to dominate. This is also the time (indicated by thick line) that an ENA imaging sequence was obtained (Daglis et al., submitted manuscript, 2003), clearly showing the conversion from an asymmetric ring current on open drift paths to a symmetric ring current on closed drift paths. As the late recovery phase proceeds, charge exchange losses reach values twice as large as flow-out losses. The late recovery phase is inter- rupted by small injections during which flow-out losses again become important.

[30] The June 1991 storm was more complex than the September 1998 storm; this is reflected in the $D s t^{*}$ profile (left-hand side of Figure 8). A critical difference of the June 1991 storm is the high abundance of energetic $\mathrm{O}^{+}$in the ring current. As shown by Daglis [1997a], $\mathrm{O}^{+}$ions dominated the ring current during the main phase of all intense storms in 1991, including the June 1991 storm. A particular characteristic of the June storm was the exceptionally long-lived high level of $\mathrm{O}^{+}$. Daglis [1997a] noted that the prerequisite of such a long-lived high abundance of $\mathrm{O}^{+}$in the ring current is a fast and prolonged feeding of the inner plasma sheet by the ionospheric ion source, as previously discussed by Daglis and Axford [1996].

[31] An immediate and decisive effect of the $\mathrm{O}^{+}$dominance during intense space storms is the fast decay of the ring current due to the much shorter charge-exchange loss time-scales of energetic $\mathrm{O}^{+}$as compared with $\mathrm{H}^{+}$[Daglis, 1997a, 1997b]. This effect of compositional variations, which is critical for storm dynamics, had been discussed by Tinsley and Akasofu [1982] a few years before the first appropriate, comprehensive measurements by AMPTE/ CCE, which covered the full energy range of the stormtime ring current [Hamilton et al., 1988]. 
[32] The simulation (Figure 8) confirms this effect for the June 1991 intense storm. In the left-hand side of Figure 8 we see again the dominance of flow-out losses during the storm main phase, actually at both Dst minima of June 5 . However, the decrease of the flow-out losses starts relatively early and the early recovery losses are already dominated by charge exchange, which is quite different from the September 1998 picture. Just after the first storm maximum (Dst minimum) near $0800 \mathrm{UT}$, charge exchange becomes the dominant loss process until the start of the second storm maximum around 1300 UT. During the second Dst dive, flow-out losses dominate to subside again at the second Dst minimum at 2000 UT, when charge exchange dominates for more than 4 hours, until well after 0100 UT on 6 June. This time interval marks the initial fast recovery of Dst. Flow-out losses dominate again for several hours until after $1000 \mathrm{UT}$, when the late recovery phase starts, with the majority of ions trapped on closed drift paths and charge exchange dominant again.

[33] The complex interplay between flow-out and charge exchange losses during the June 1991 storm is presumably the combined effect of IMF fluctuations and ring current composition. The IMF fluctuations influence the convection electric field and consequently the convection pattern of the incoming ions and their loss through the dayside magnetopause, while the $\mathrm{O}^{+}$dominated ring current favors rapid decay through charge exchange. This is evident in the early, fast recovery phases of the storm and even more in the late recovery, when charge-exchange losses were larger than flow-out losses by as much as a factor of 5 to 10 , while this factor was just 2 in the September 1998 storm recovery phase. In fact the CRRES-based estimates of ring current decay time scales (Daglis et al., submitted manuscript, 2003) referred to a time interval in which charge exchange exceeded flow-out loss by as much as a factor of 5 (indicated by the thick black line in Figure 8). The analysis of the CRRES ion distributions confirmed that chargeexchange was a major loss mechanism during this time interval.

[34] The September 1998 storm occurred during the rise from solar minimum conditions and thus oxygen was not the dominant ion species. The June 1991 storm, on the other side, occurred during solar maximum conditions and had a dominant $\mathrm{O}^{+}$ring current population. Hence there is a clear difference in the recovery mode between solar minimum and solar maximum storms. Charge exchange appears a more important decay agent in solar maximum storms, which have a dominant $\mathrm{O}^{+}$component.

\section{Critical Information From the Global Energy Balance}

[35] The Ring Current-Atmosphere Interaction Model (RAM) provides a measure of the energy input to the ring current region completely independent of upstream solar wind parameters. The RAM energy input function describes the total energy flowing into the inner magnetosphere through the nightside outer boundary plus the net adiabatic energization of the drifting ions within the model volume. The inflowing energy flux is calculated using nightside outer boundary ion distributions measured by the LANL geosynchronous satellites and the modified McIlwain con- vection electric field (which is a function of $K p$ and is scaled by the polar cap potentials from the AMIE model). RAM also provides global energy-loss time scales which integrate the effects of flow-out, charge-exchange, and Coulomb collisional losses, again completely independent of upstream solar wind quantities. The question is how do the energy input and loss functions calculated in RAM compare to statistical functions obtained by correlating Dst and upstream solar wind parameters over hundreds of storms and all phases of the solar cycle [c.f. O'Brien and McPherron, 2000]. Simple energy balance models based on these statistical energy input functions and global loss time scales have had great success in predicting the Dst index during magnetic storms [c.f. Burton et al., 1975; O'Brien and McPherron, 2000].

[36] Figure 9 is a comparison of energy input, energy loss time scales and $D s t^{*}$ between the RAM simulation and two energy balance models, Burton et al. [1975] and O'Brien and McPherron [2000] (hereafter BMR and OM, respectively), for both the June 1991 (left side) and September 1998 (right side) magnetic storms. The RAM energy input function is plotted in Figure 9d. The quantities used to calculate this energy input function are the plasma sheet density and temperature on the nightside at geosynchronous orbit as measured by the LANL MPA instrument (density plotted in Figure 9b) and the convection electric field (proportional to solar wind $\mathrm{E}_{y}$, plotted in Figure 9c). In contrast the energy input functions of BMR and OM (plotted for comparison in Figure 9d) depend only on solar wind $E_{y}$. The magnitude and location of the maxima in the energy input functions from all three models are in good general agreement. As expected, the statistical energy input functions vary in the same manner as the solar wind $E_{y}$. The RAM energy input function varies as $E_{y}$ but is also modulated by the plasma sheet density. This is especially important for the September 1998 magnetic storm. The doublepeaked nature of the solar wind $E_{y}$ produced a strong doublepeaked signature in the statistical energy input functions of BMR and OM. However, the RAM energy input has only a single maximum associated with the first solar wind $E_{y}$ peak. The sharp drop in the plasma sheet density produces a much weaker energy input in association with the second solar wind $E_{y}$ peak. The effects of this can be clearly seen in the resulting $D s t^{*}$ index (Figure 9a). The $D s t^{*}$ predicted by $\mathrm{BMR}$ and OM show evidence of the double-peak in energy input. The minimum $D s t^{*}$ is reached in association with the second maximum in the energy input function. The predicted $D s t^{*}$ profile is much wider than the observed profile and the predicted minimum $D s t^{*}$ occurs later in time than the observed minimum. The RAM model closely reproduces both the minimum $D s t^{*}$ value and the $D s t^{*}$ profile. This is of considerable interest since the second peak in solar wind $E_{y}$ (which did not produce a corresponding peak in energy input) was produced by the southward IMF $B_{z}$ portion of a magnetic cloud. The first and more geoeffective peak in solar wind $E_{y}$ occurred in association with the sheath preceding the cloud. In this case the magnetic cloud was less geoeffective even though it contained significant southward fields [c.f. Gonzalez and Tsurutani, 1987].

[37] The June 1991 plot shows a similar effect of the plasma sheet density on the energy input. The BMR and OM statistical energy input functions reflect the structure of 

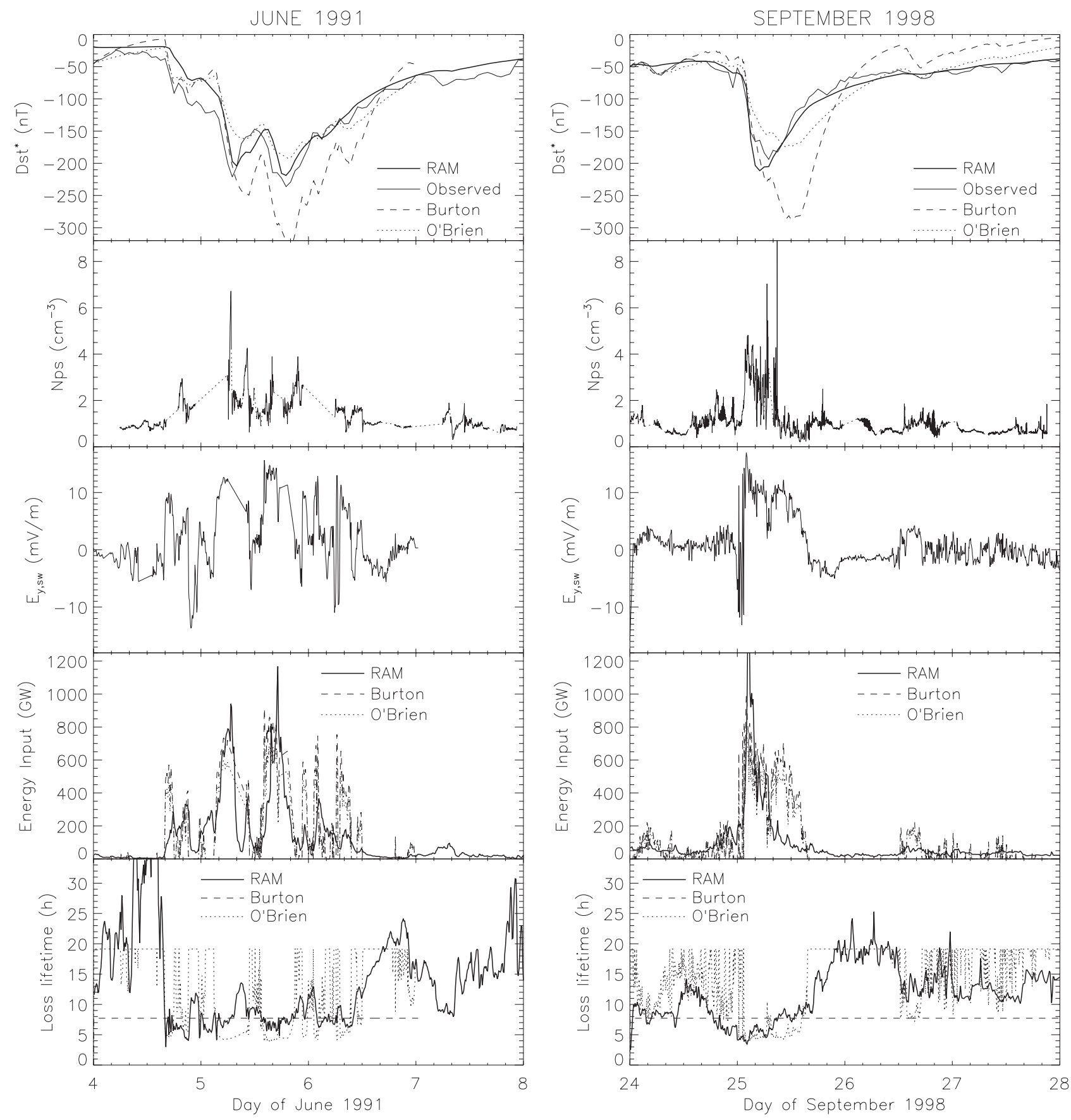

Figure 9. Comparison (a) between observed $D s t^{*}$ and that calculated by the RAM model and predicted by the models of [Burton et al., 1975] and [O'Brien and McPherron, 2000] for the June 1991 (left side) and the September 1998 (right side) storms. Also shown are the energy-input functions (d) and the global loss time-scales (e). The statistical energy input functions are proportional only to the solar wind $E_{y}$ (c) and thus are multi-peaked. The RAM model energy input function is proportional to the product of the nightside plasma sheet density observed by the LANL geosynchronous spacecraft (b) and the convection velocities.

the solar wind $E_{y}$. However, the RAM energy input peaks at 0600 UT and 1700 UT on 5 June are narrower than those predicted based on solar wind $E_{y}$ due to the structure in the plasma sheet density. Except for the very narrow spikes, these two RAM energy input peaks are comparable in magnitude and width even though the electric field is significantly higher for the second peak. This is because the plasma sheet density is lower for the second peak at 1700 UT. In fact, the double-peaked structure in the energy input at 1700 UT (seen in the statistical energy input functions) is lost in the RAM energy input function because the second peak in the electric field occurs after a sharp drop-off in the plasma sheet density. These differences in the energy input again produce important differences in the 
$D s t^{*}$ predicted by these models (Figure 9a). Again, the RAM $D s t^{*}$ is in excellent agreement with the observed $D s t^{*}$ both in the magnitude and the location of the two minima, which are of comparable size. BMR predicts a much deeper and wider second minimum in $D s t^{*}$ than observed. OM also predict very different magnitude and width of the two minima but underpredict the $D s t^{*}$ values compared to observations.

[38] Global loss time-scales from all three models are plotted in Figure 9e. The RAM time scale for loss (thick line) is due to the combined effects of flow-out loss, Coulomb collisions, and charge-exchange collisions. BMR assume a constant 7.7 hour time scale for loss (dashed line). The OM time-scale is a function of the solar wind $E_{y}$ (dots). September 1998 is a simple storm with a single $D s t^{*}$ minimum followed by a clear two-phase recovery so it is examined first for the overall variation in global loss time scales in the RAM model. The September 1998 storm did not start from a quiet-time baseline; $D s t^{*}$ values were already at $-50 \mathrm{nT}$ early on September 24 and returned to this value again on September 27 following the magnetic storm. Loss lifetimes early on September 24 reached 20 hours, consistent with charge-exchange of a trapped ion population. The ring current began to build at 0000 UT on 25 September and reached its minimum $D s t^{*}$ at $\sim 0400$ UT. Loss lifetimes immediately decreased during this period reaching as low as $\tau=3$ hours. Recovery began around 0400 UT. At this time loss lifetimes increased slowly reaching values of $\tau \sim 20$ hours by 0000 UT on 26 September. The transition between early and late recovery phase occurred near 1800 UT on 25 September.

[39] The June 1991 magnetic storm had a much more complicated main phase but the general behavior of the lifetime for loss in the RAM model is similar. Early on 4 June, RAM loss lifetimes were $\tau \sim 20$ hours with $D s t^{*}$ values near $-50 \mathrm{nT}$. Late in the recovery phase on 7 June, loss lifetimes again reach values of 20 hours. During the multiple intensifications in the main phase, $\tau$ reached values near 3 hours. After each intensification an interval of recovery occurs, where lifetimes again increase to values between 10 hours and 20 hours. The BMR constant $\tau=7.7$ hours clearly does not reflect the variations in the loss time scales but is not a bad average value during the main phase and the early recovery phase. The late recovery phase ring current probably decays too rapidly in the BMR energy balance model as a result. The OM prediction of time scales for loss as a function of solar wind $E_{y}$ agrees remarkably well with the RAM model results during the main phase (dominated by flow-out loss) and during the late recovery phase (dominated by charge-exchange loss) but not during the early recovery phase (where flow-out loss is important).

[40] Figure 10 is a scatter plot of the global time scales for loss from RAM against the simultaneous upstream solar wind $E_{y}$ value (no time lags are considered). The $\mathrm{OM}$ statistical formula relating $\tau$ and solar wind $E_{y}$ is plotted for comparison. The OM formula is only valid for positive $E_{y}$ values and is held constant at $\tau=19$ hours for negative $E_{y}$ values. The agreement between the two plots based on very different techniques is remarkable. Loss time scales are fast for large positive values of $E_{y}$ during the storm main phase. They reach values near 1 hour for the June 1991 event and near 2 hours for the September 1998 event during

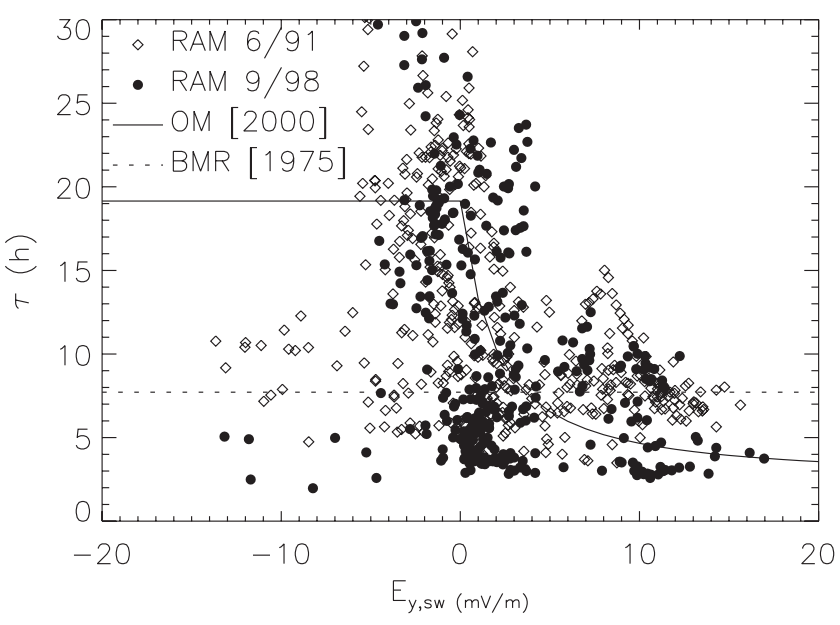

Figure 10. Scatter plot of the global decay time scales from the simulated June 1991 and September 1998 magnetic storms versus the upstream solar wind $E_{y}$ value. Plotted for comparison is the statistical relationship between $E_{y}$ and decay time scales derived by [O'Brien and McPherron, 2000].

the main phase. These fast loss time scales are due to flowout of material on open drift paths to the dayside magnetopause. The transition from short to long loss time scales appears to be a function of the solar wind $E_{y}$ and occurs as $E_{y}$ is transitioning from high values (associated with the main phase) to zero. Loss time scales (now associated mainly with charge-exchange decay) continue to increase as recovery proceeds due to the progressive removal of populations with shorter charge-exchange lifetimes (i.e., $\mathrm{O}^{+}$ ions) but this is not correlated with positive solar wind $E_{y}$ values. The conversion of drift paths from open to closed and the subsequent changeover from fast flow-out loss time scales to slower charge exchange time scales appears to be responsible for the two-phase decay. This is clearly the case for the September 1998 storm. For the June 1991 storm, charge exchange losses are important both during the main phase and during the early recovery phase because of the dominant $\mathrm{O}^{+}$population. This characteristic difference introduces a mechanism for variations in the loss time scale with solar cycle, because of the solar-cycle dependence of the $\mathrm{O}^{+}$abundance in the magnetosphere [e.g., Lennartsson, 1989]. One should also note that the choice of convection pattern effects the relative importance of charge-exchange and flow-out loss during the main and early recovery phases. Convection patterns that bring inner plasma sheet source populations in closer to Earth or keep the plasma there over longer time intervals increase the chargeexchange loss.

[41] Also plotted in Figure 10 is the statistical relationship between $E_{y}$ and decay time-scales derived by $O$ 'Brien and McPherron [2000], showing a statistical correlation between ring current loss rates and solar wind $v B_{s}$. Loss of ions on open drift paths to the dayside magnetopause in the presence of a diminishing plasma sheet source population can account for the relationship between $v B_{s}$ (related to magnetospheric convection) and loss time scales. The ring current loss time scales plotted against $E_{y}$ in Figure 10 follow the trends predicted by O'Brien 

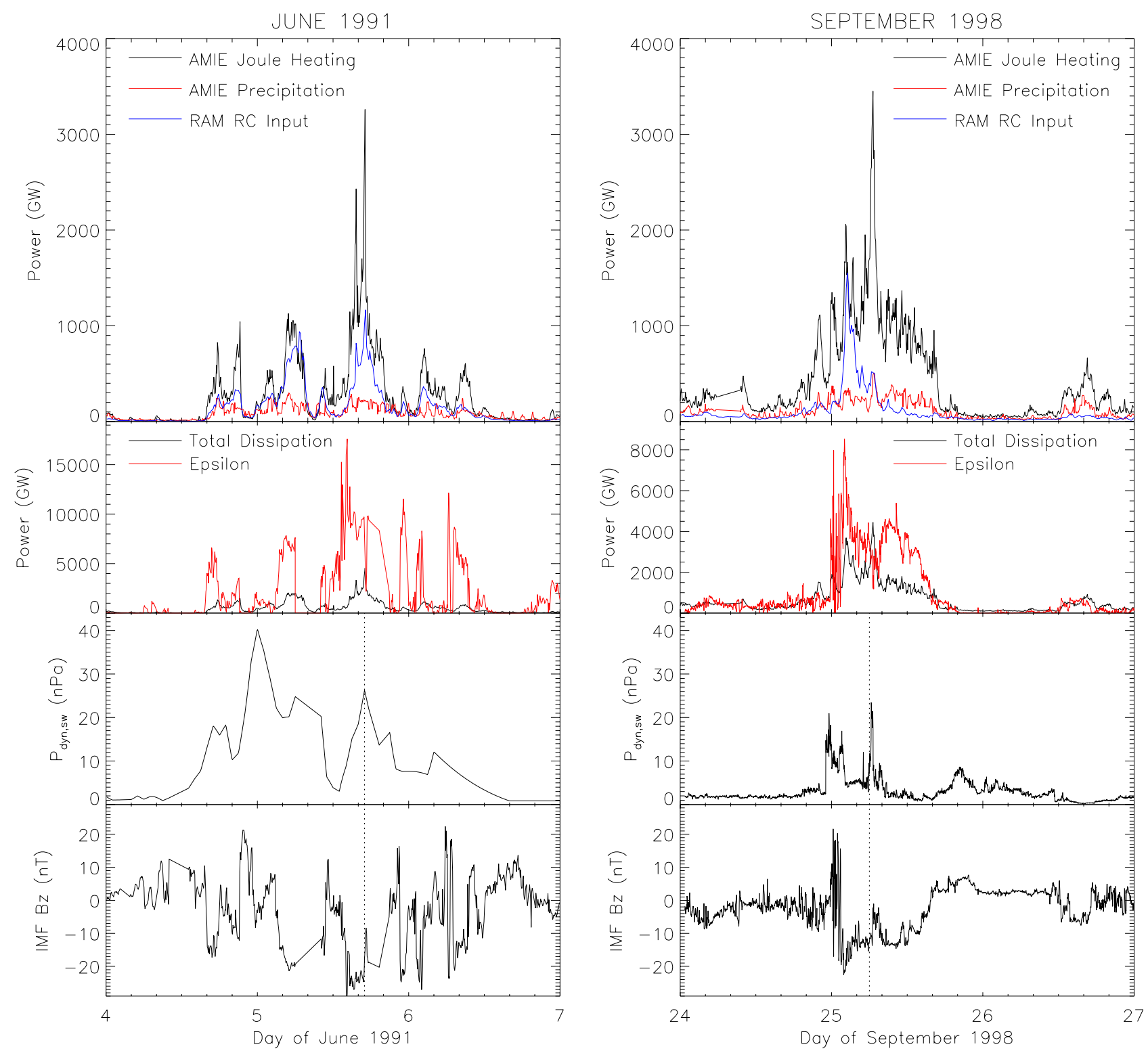

Figure 11. Global energy budgets for the June 1991 and September 1998 storms. From top to bottom: (a) the energy input from the RAM model, and the energy dissipated in Joule heating and particle precipitation estimated by the AMIE model. (b) The sum of the three energy losses in Figure 11a to the total storm energy input estimated using the epsilon parameter. (c) The solar wind dynamic pressure. (d) The IMF $B_{z}$ component. The largest Joule heating spikes for each storm occur in association with a storm-time substorm triggered during a period of high solar wind dynamic pressure when the already southward IMF began to turn northward (i.e., became less southward) for a brief period.

and McPherron offering evidence in support of this suggestion.

[42] It is clear that the RAM model reproduces the $D s t^{*}$ values (both the absolute magnitude and profile) for the selected storm events. Energy budgets are constructed for these magnetic storms using the RAM energy input function to represent energy dissipation in the ring current. Global Joule heating and particle precipitation are estimated from the AMIE model based on magnetometer and satellite observations from these two magnetic storm intervals. The values from the AMIE model are doubled to represent both hemispheres. Figure 11 is a plot of the energy dissipated versus time into the ring current, Joule heating and particle precipitation (Figure 11a for each storm). During both storms, Joule dissipation clearly dominates all other energy sinks. Ring current energy input is the second largest. Figure $11 \mathrm{~b}$ compares the sum of the three energy losses in Figure 11a to the total storm energy input estimated using the epsilon parameter [Akasofu, 1981]. The epsilon parameter assumes that the reconnection region on the dayside magnetopause has a constant $7 R_{E}$ scale length. The combined storm energy dissipation in Joule heating, particle precipitation, and ring current energy is always much smaller than the estimated magnetic storm energy input. The energy dissipated in plasmoids moving down the magnetotail into the solar wind has not 
been included in this estimate and may account for some of this difference.

[43] Figures 11c and 11d for each event give the solar wind dynamic pressure and IMF $B_{z}$, respectively. Large peaks in the Joule dissipation (identified as major substorms in the midlatitude magnetometer records) occur for both events during intervals of high solar wind dynamic pressure when a northward turning of the IMF occurs within a southward IMF interval. These major Joule heating peaks are marked by dotted vertical lines for each event. Both northward turnings of the IMF and high solar wind dynamic pressure intervals are known to be triggers of substorm expansion. In either case, substorm triggering is more likely when the IMF had been southward (or horizontal) with large magnitude for at least $30 \mathrm{~min}$ prior to the substorm event [Burch, 1972; Kokubun et al., 1977] as was the case for these storm events. Apparently, when both a northward turning of the IMF and a dynamic pressure enhancement occur simultaneously during a long interval of southward IMF, a major substorm is triggered, reconfiguring the magnetotail on a global scale. A large portion of the stored energy in the tail is released as Joule heating and particle precipitation creating intense spikes in the energy dissipation profiles for these storms. Magnetometers at midlatitudes clearly saw the signature of these two major substorms, as described in section 2. Smaller peaks in Joule dissipation are associated with high solar wind dynamic pressure during intervals of southward IMF. At 0000 UT on 5 June, a peak in solar wind dynamic pressure occurred during northward IMF $B_{z}$ conditions and only a minor increase in Joule heating resulted.

[44] The major energy sinks, presented in Figure 11, are integrated over a 3-day period for each storm and compared to estimated energy input using the epsilon parameter, the pressure-corrected epsilon parameter and the [Burton et al., 1975] energy input function, $F(E)$. These quantities are presented in Table 1 . The energy contained in the stretched magnetotail is estimated by [Nakamura et al., 1997] at $5 \times$ $10^{15} \mathrm{~J}$. The two storms dissipated roughly the same amount of energy distributed among the various energy sinks. Joule heating represented the major energy sink in both storms. However, the ring current accounted for more of the storm energy in the June 1991 event $-30 \%$ as opposed to $18 \%$ during September 1998. Interestingly enough, in the September 1998 event, almost equal amounts of energy were channeled into the ring current and particle precipitation. The summed energy sinks in the June 1991 event accounts for only $\sim 29 \%$ of the total storm energy input estimated from epsilon, but it accounts for $66 \%$ of epsilon in the September 1998 event. When compared to the pressurecorrected epsilon, the dissipated energy estimated from RAM and AMIE accounts for $20-30 \%$ in both events. As in past studies, the RAM energy input is in excellent agreement with both $\mathrm{F}(\mathrm{E})$ and $\mathrm{Q}(\mathrm{E})$; even though the RAM energy input is calculated completely independent of upstream solar wind parameters. $F(E)$ and $Q(E)$ are statistical fits based on solar wind parameters.

\section{Toward Space Storm Forecasting}

[45] The need for space storm forecasting has become apparent during the last decade, arising from the recognition
Table 1. Space Storm Energy Budget

\begin{tabular}{|c|c|c|}
\hline & 4-7 June 1991 & 24-27 September 1998 \\
\hline \multicolumn{3}{|c|}{ Integrated Solar Wind Energy Input } \\
\hline$\epsilon^{\mathrm{a}}$ & $4.74 \times 10^{17} \mathrm{~J}$ & $2.55 \times 10^{17} \mathrm{~J}$ \\
\hline$\epsilon^{\prime b}$ & $6 \times 10^{17} \mathrm{~J}$ & $2.5 \times 10^{17} \mathrm{~J}$ \\
\hline $\mathrm{F}(\mathrm{E})^{\mathrm{c}}$ & $4.3 \times 10^{16} \mathrm{~J}$ & $3.3 \times 10^{16} \mathrm{~J}$ \\
\hline $\mathrm{Q}(\mathrm{E})^{\mathrm{d}}$ & $2.79 \times 10^{16} \mathrm{~J}$ & $2.47 \times 10^{16} \mathrm{~J}$ \\
\hline \multicolumn{3}{|c|}{ Integrated Magnetospheric Energy Dissipation } \\
\hline $\begin{array}{l}\text { Ring Current } \\
\text { Input - RAM }\end{array}$ & $3.9 \times 10^{16} \mathrm{~J}(29.2 \%)$ & $2.7 \times 10^{16} \mathrm{~J}(16.1 \%)$ \\
\hline Precipitation - AMIE & $2.2 \times 10^{16} \mathrm{~J}(16.5 \%)$ & $3.0 \times 10^{16} \mathrm{~J}(17.9 \%)$ \\
\hline Joule Heating - AMIE & $6.8 \times 10^{16} \mathrm{~J}(50.6 \%)$ & $1.1 \times 10^{17} \mathrm{~J}(63.1 \%)$ \\
\hline Magnetotail stretching ${ }^{\mathrm{e}}$ & $5.00 \times 10^{15} \mathrm{~J}(3.7 \%)$ & $5.00 \times 10^{15} \mathrm{~J}(3.0 \%)$ \\
\hline Total & $1.3 \times 10^{17} \mathrm{~J}$ & $1.7 \times 10^{17} \mathrm{~J}$ \\
\hline \multicolumn{3}{|c|}{ Integrated Energy Comparisons } \\
\hline$($ Total Dissipation) $/ \epsilon$ & $28.7 \%$ & $65.9 \%$ \\
\hline (Total Dissipation) $/ \epsilon^{\prime}$ & $21.6 \%$ & $68 \%$ \\
\hline (Ring Current Input)/F(E) & $90.7 \%$ & $81.8 \%$ \\
\hline (Ring Current Input)/Q(E) & $149.5 \%$ & $122.7 \%$ \\
\hline
\end{tabular}

${ }^{\mathrm{a}}$ As defined by Akasofu [1981]

${ }^{\mathrm{b}}$ As defined by Monreal-MacMahon and Gonzalez [1997].

${ }^{\mathrm{c}}$ As defined by Burton et al. [1975].

dAs defined by O'Brien and McPherron [2000].

${ }^{\mathrm{e}}$ From Nakamura et al. [1997].

of the severity of technological impacts of space weather. In recent years we have been confirming that spacecraft systems and subsystems show a susceptibility to effects of the space environment including communication, navigation, and reconnaissance satellite operational anomalies. There is an increasing trend for modern systems, probably due to "softer" designs of electronic components, reduction in subsystem sizes, and increases in performance demands. Moving to lower altitudes, high-frequency (HF and VHF) wireless communication links through the ionosphere, which are used for some national defense communications and for civil emergency communications, are significantly affected by changes in ionospheric properties produced by space weather. Geomagnetically induced currents (GIC) in technological systems, such as electric power transmission systems, oil and gas pipelines, long-distance telephone cables (including fiber optics) and railway equipment, are a manifestation of space weather at the Earth's surface. The most critical effect is the saturation of transformers through GICs, which may lead to problems in the operation of the system, and even to a collapse of the whole system and to permanent damages of transformers.

[46] Increasing space activities of modern society, as well as future planetary exploration, demand a thorough knowledge of the dynamics of the space environment. Space weather dynamics and impacts on society are challenges for the scientific community, but also the spacecraft industry, airline companies, defense forces, oil and mineral industries, electric power industry, insurers, telecommunications companies, users and providers of positioning systems. "Space climatology" is in a position similar to meteorology in the beginning of the 20th century. Because of the special physical interest and complexity of space storms as well as their impact on expensive and societally significant technological systems, there is a strong motivation for thorough understanding of space weather dynamics and for improvement of the functionality of forecasting tools. 
[47] The coupled solar wind-magnetosphere system is a large-scale natural system, which can be characterized as an input-output system [c.f. Price and Prichard, 1993; Vassiliadis and Daglis, 1994]. In spite of being driven by the turbulent solar wind, the magnetosphere exhibits global coherence, as shown by many studies using nonlinear dynamical techniques [Sharma, 1995]. There is accumulating evidence of the low dimensionality of the magnetosphere, although the specific value of the dimension may not be obtained readily using the techniques of phase space reconstruction, which have been developed for autonomous systems in general [e.g., Abarbanel et al., 1993]. The application of these techniques to the auroral electrojet indices have shown evidence that the magnetosphere exhibits low-dimensional behavior [Vassiliadis et al., 1990; Sharma, 1995] and thus can be described by a small number of variables obtained from time series data. The extension of these techniques to input-output systems is more appropriate for modeling the solar wind-magnetosphere system [Casdagli, 1992; Vassiliadis and Daglis, 1994]. Using this technique, nonlinear filters relating the input (solar wind variables) to the output ( $A L$ index) can be computed and these show that a relatively small number of magnetospheric state variables dominate the dynamics [Vassiliadis et al., 1995]. Such nonlinear dynamical models of the magnetosphere derived from observational time series data through the use of phase space reconstruction techniques have given new advances in the understanding of magnetospheric dynamics. In particular the recognition that the dynamics is dominated by global features that may be described by a small number of variables forms the basis for the predictability of the magnetospheric dynamics. The modeling of geomagnetic activity using time series data has resulted into models of the solar wind-magnetosphere coupling and forecasting tools for space weather. The predictability of space storms is an important aspect of the nonlinear dynamical modeling of the magnetosphere. Forecasts of storms (Dst) and substorms $(A L)$ using the solar wind data from ACE spacecraft are now routinely available.

[48] The OMNI database has been used to reconstruct the solar wind-magnetosphere system during storms and to predict storms using current solar wind input. The solar wind induced electric field given by the product $v B_{s}$ of the solar wind speed $v$, and the southward component of the magnetic field $B_{S}$ is taken as the input and the Dst index as the magnetospheric output during storms. The predictions using such nonlinear dynamical models constructed from this correlated data set yield Dst values with an average error of $8 \mathrm{nT}$ [Valdivia et al., 1996].

[49] The magnetic storm of 25 September 1998 has been studied using the high-resolution data of the solar wind and the magnetic field perturbations at the ground-based magnetometer stations. To develop the dynamical models in the reconstructed phase space the 5-min averaged data of January-June 1979, consisting of solar wind variables from IMP-8 and the ground magnetometers, is used for the phase space reconstruction during storms. Using this reconstructed space and the solar wind data, the Dst index for the magnetic storm of 25 September 1998 is predicted using linear and nonlinear models (Figure 12). The solar wind induced electric field $v B_{s}$ is shown in the top panel of Figure 12 and the lower panel shows the actual (black curve) and predicted Dst (blue and red curves). A linear model similar to the Burton et al. [1975] model yields the blue curve in Figure 13 and the nonlinear model yields the red curve. The nonlinear model does a better job of predicting the magnitude of the storm but both linear and nonlinear models miss the storm peak. This is consistent with the RAM model results, which show that a drop in plasma sheet densities triggered a ring current decay during the second part of this storm. Neither the linear nor the nonlinear models take this type of density variations into account.

[50] The phase space reconstruction technique can be extended to model the magnetic field perturbations at the midlatitude stations, instead of the Dst index [Valdivia et al., 1999]. The data base of January-June 1979 is used to construct the nonlinear models and the predictions of the $\mathrm{H}$ component of the magnetic field at the midlatitude stations are compared with the actual values in Figure 13. The predictions for the different stations from the linear model are the blue curves and those from the nonlinear models are the red curves. It is apparent that the predictions in both the linear and nonlinear cases for the different stations do not differ much from each other. This could be due to the limited data set of storms (four with Dst less than -100 Dst) in the data base of January-June 1979 used for developing the models.

[51] The geomagnetic indices are convenient variables for studying the complex dynamics of the magnetosphere and are widely used. However, they suffer from limitations due to the loss of information associated with their definitions [c.f. Akasofu et al., 1983; Kamide and Akasofu, 1983]. Considering the inherent nonlinearity of the magnetosphere, it is important to use measures that are appropriate for nonlinear systems. The mutual information between two variables is a measure of the correlation between them and is computed from the joint probability as well as the separate probabilities. In the case of reconstructed phase space the average mutual information (AMI) functional $\mathrm{I}(\tau)$ is defined in terms of the probability distribution functions for the time delay $\tau$. The AMI of a nonlinear dynamical system yields the coherence or memory time before dynamical information is lost and are computed from the time series data [Fraser and Swinney, 1986]. Considering the differences in magnetospheric dynamics during quiet and active periods, the AMI for these periods have been computed from the $A L$ index and the magnetic field measurements at 11 magnetometer stations for the period January-June 1979 [Edwards et al., 2000]. For active periods the coherence time for $A L$ was found to be less than $10 \mathrm{~min}$ and for the individual stations it ranged from 10 min to $30 \mathrm{~min}$, thus showing considerable loss of information when $A L$ is used instead of the magnetometer data. The construction of the $A L$ index as an envelope of the $\mathrm{H}$ component of the magnetic field can be viewed as a randomization process. This is a loss of information and is evident in the lower coherence time for the $A L$ index compared with those of the separate stations. However, for quiet periods the AMI for $A L$ lies within the range of values for the magnetometer stations. This indicates that during quiet periods the disturbances at the magnetometer stations are largely uncorrelated and thus the $A L$ index does not introduce a further randomization. 


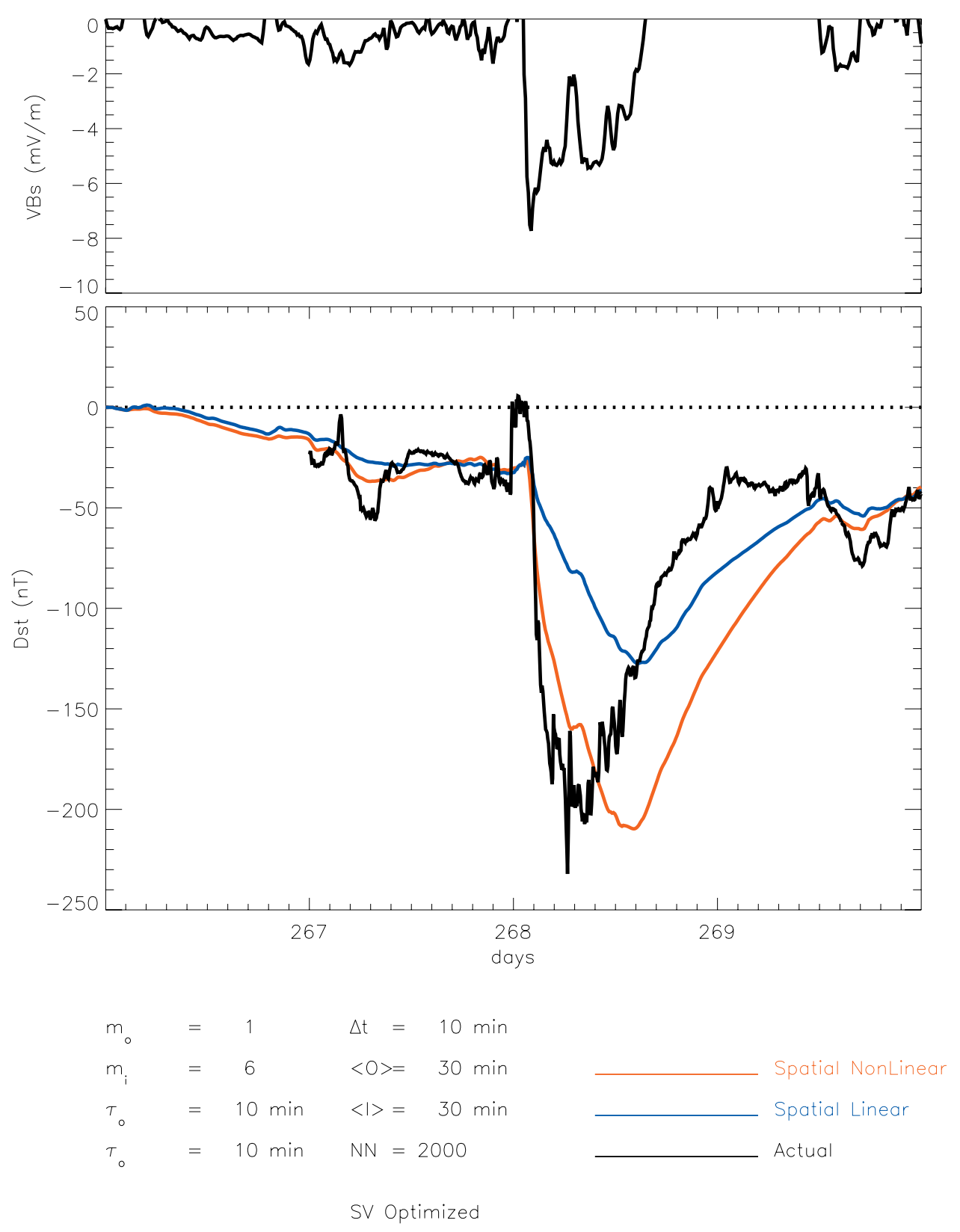

Figure 12. The magnetic storm of 25 September 1998. The top panel shows the solar wind induced electric field and the botttom panel shows the actual Dst (black curve) and the Dst predicted using linear (blue curve) and nonlinear model (red curve). The nonlinear model predicts the peak of the storm better but both the linear and nonlinear models miss the storm peak by about the same offset in time.

[52] The average mutual information for the storm period 24-27 September 1998 are shown in Figure 14. The corresponding time scales are usually defined when the function $\mathrm{I}(\tau)$ plotted in Figure 14 has a value of 0.5 . The continuous curves corresponding to the different magnetometer stations yield a wide range of time scales starting from about $10 \mathrm{~min}$. The coherence time for Dst obtained from the dashed curve in Figure 14 is about $25 \mathrm{~min}$.

[53] Since Dst is essentially an average of the H component of the magnetic field measured at the midlatitude stations, its coherence time is expected to be between those of the individual stations. This is indeed the case, as shown by the average mutual information curves in Figure 14 . However, it should be noted that the AMI curve for Dst (dashed curve in Figure 14) does not lie in the middle of the AMI curves for the individual stations. This shows that the dynamical features obtained from Dst are not a simple average of those obtained from the individual magnetometer stations, reflecting the nonlinearity of magnetospheric behavior.

\section{Summary Discussion}

[54] In this paper we have attempted to assess several open issues and disputed paradigms of space storm dynamics. A significant advancement in our knowledge has been the empirical recognition that the prolonged southward orientation of the interplanetary magnetic field is the main driver of 

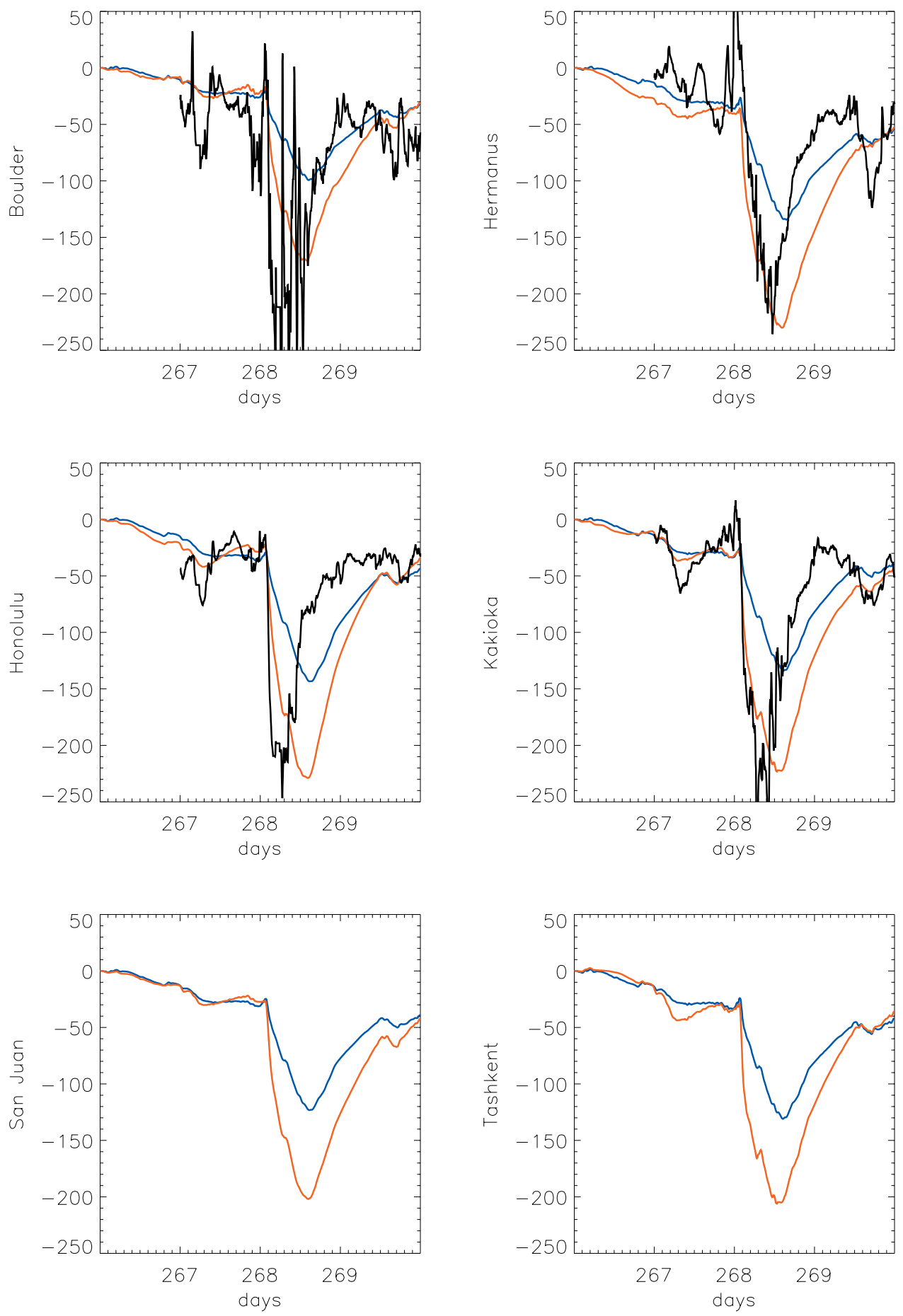

Figure 13. The magnetic field perturbations (H component) at six midlatitude stations during the storm of 25 September 1998. The actual measurements (black curves) are compared with the predictions using linear (blue curves) and nonlinear (red curves) models. The predicted magnetic field values, both from linear and nonlinear models, do not change much from one station to the other, although the linear model under estimates the storm strength compared to the nonlinear model.

space storms [Gonzalez and Tsurutani, 1987; Tsurutani, 2001]. However, simulations have shown that this driver is conditioned by internal magnetospheric conditions. We have shown that the plasma sheet density is of critical importance to the eventual result of the interplanetary drivers, as measured by storm intensity. Variations in the plasma sheet density significantly modified the geoeffectiveness of southward IMF regions in the solar wind (see Figure 9). During the June 1991 storm the energy inputs associated with the two major regions of southward IMF were of comparable magnitude and duration due to the modulating effects of the highly structured plasma sheet density. 


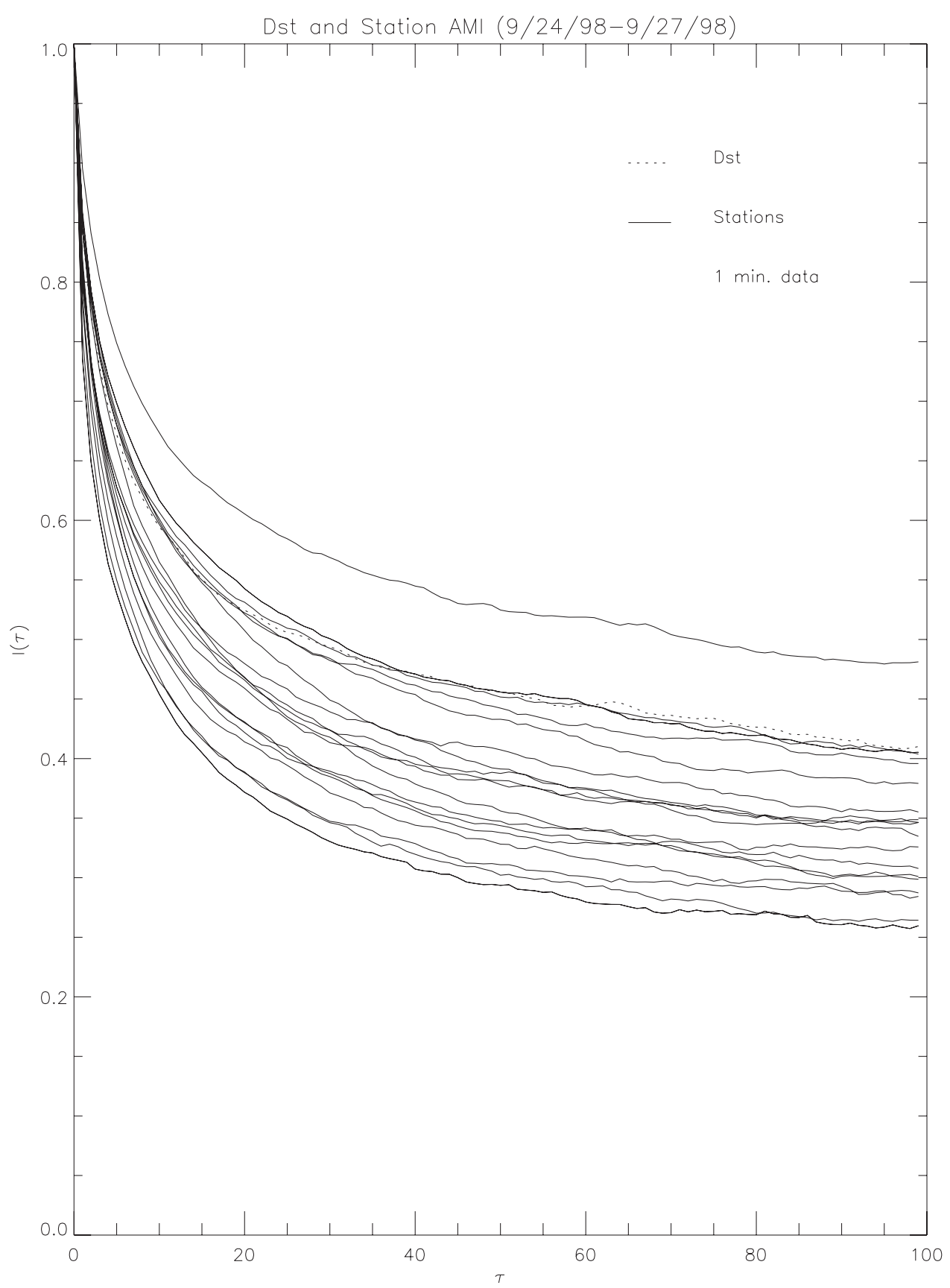

Figure 14. The average mutual information function $I(\tau)$ computed from the $\mathrm{H}$ component of the magnetic field at midlatitude stations. The dashed curve correspond to Dst and the thick lines to the different stations. The value of $\tau$ corresponding to $I(\tau)=0$ is defined as the coherence time and has values in the range $10-30 \mathrm{~min}$.

[55] Among the hottest issues in storm research is the relationship between storms and substorms [e.g., Kamide et al., 1998b; Daglis and Kamide, 2003]. During the main phase of a magnetic storm, a number of intense substorms occur successively. During substorms a significant amount of energy is deposited in the polar ionosphere and the inner magnetosphere [e.g., Elphinstone, 1996; Baker et al., 1996]. Storms and substorms are, in a sense, mainly low-latitude and mainly high-latitude phenomena, respectively. The coupling of these two phenomena has become a matter of debate during the last few years.
[56] While substorms had been proposed as integral ("sub") parts of storms by S. Chapman and S.-I. Akasofu [c.f. Chapman, 1962; Akasofu, 1968], several studies now suggest that substorms do not have massive effects in the "battle." Remarkably, the disagreements on the storm-substorm relationship have been based on studies addressing the relationship between the $A E$ (or $A L$ ) "substorm index" and the Dst "storm index" [Iyemori and Rao, 1996; McPherron, 1997], rather than the relationship between storms and substorms. However, we ought to eventually distinguish between storms and Dst, simply because Dst is 
not the super-accurate index we used to think of. Nevertheless, and despite some isolated extreme polemic against Dst [Campbell, 1996], there is a general consensus of the community that the pressure-corrected $D s t^{*}$ index is mainly a signature of the ring current. The key point of Campbell [1996] was that the storm-time Dst profile can be fitted with a log-normal distribution. Since it has been shown that lognormal distributions can be produced by a large number of superposed systems decaying with different decay time constants, [Campbell, 1996] argued that a large number of ionospheric current systems produce the Dst index and that consequently there is no such thing as a ring current. However, the ring current is composed of ions with a rather wide range of $L$-shells, energies, pitch-angles, and masses. The global ring current decay rate, expressed by the $D s t$ variation, is simply the superposition of all these numerous decay rates, and thus naturally explains the log-normal distribution.

[57] Another argument against substorm significance has been the fact that during nonstorm substorms, the ring current intensification is much less than during storm-time substorms, appears only at lower ring current energies, and occurs further out at $L$-values between 5 and 7 [Korth et al., 2003]. A rough correlation of $A E$ to Dst shows that a series of $A E \sim 800-1000 \mathrm{nT}$ events leads to a change of Dst of $\sim 30$ nT. However, [Daglis, 2001] pointed out that the antisubstorm polemic is based on the (usually untold) a priori assumption that storm-time substorms do not differ from nonstorm substorms, hence the "inability" of nonstorm substorms to produce storms condemns all substorms to "storm-impotence", although there are no sound research results that could justify this assumption [Daglis and Kamide, 2003].

[58] In an effort to approach the substorm-storm problem from a different perspective, we applied a spatio-temporal analysis technique of midlatitude magnetometer measurements. The resulting UT-LT diagrams (section 2) show that substorm expansions cause significant and well-defined disturbances in the midlatitude magnetometers. These usually do not appear in Dst because the positive disturbances due the substorm current wedge often almost cancel out the negative disturbances due to the ring current enhancement. The results strongly suggest that the "classical" comparison between $D s t$ and $A L$ would best be replaced by the comparison between middle and high-latitude magnetograms.

[59] In any case the basic controversy remains as to whether the successive occurrence of substorms, i.e., the occurrence of impulsive induced electric fields, plays a substantial role in the energization of storm-time ring current particles, as compared to the action of the convection electric field [e.g., Kamide and Allen, 1997; Daglis, 2001]. This issue has been addressed in comprehensive computer simulations. Chen et al. [1994] used spike-like enhancements of the convection electric field to attempt to simulate the effect of individual substorms, while Fok et al. [1996] used an inductive localized electric field, tied to successive cycles of stretching and dipolarization of the Tsyganenko model magnetic field. Both studies concluded that the substorm contribution was subtle and possibly negative to the development of a ring current. More recently, Fok et al. [1999] made substantial modifications to their model in order to make it more realistic. The range of the ring current model was extended out to $12 R_{E}$ in the nightside magnetosphere, setting the boundary condition well outside of geosynchronous orbit, at the outer limits of the region of validity of the adiabatic bounce-averaged ring current code. This provides a plasma input that is realistically influenced by substorm-dipolarization electric fields in the inner plasma sheet. Second, a three-dimensional test particle code was used to construct the ion velocity distribution by backtracking particles from a velocity space grid to source regions assumed to have constant properties independent of the storm/substorm process. Fok et al. found that the substorm-associated induced electric fields significantly enhance the ring current by redistributing plasma pressure earthward. Accordingly, it was concluded that global convection and substorm dipolarizations do cooperate to inject plasma energy more deeply into the magnetosphere than either would individually.

[60] It is clear that simulations and their interplay with observations are of critical importance in the efforts to resolve key issues of space storm dynamics. Comprehensive modeling studies of particle acceleration [e.g., Delcourt, 2002], magnetospheric configuration and particle transport [e.g., Liemohn et al., 2001], ring current decay [e.g., Jordanova et al., 1996; Kozyra et al., 1997], waveparticle interactions [Thorne and Horne, 1994], and global energy balance [e.g., Kozyra et al., 2002] have been instrumental in achieving vital progress in space storm research. However, regarding the use of model electric fields in simulation studies, we need to be aware that the actual electric fields in the inner magnetosphere are radically different from those used in modeling. [Wygant et al., 1998] showed that during the large March 1991 storm, the large-scale electric field repeatedly penetrated earthward, maximizing between $L=2$ and $L=4$ with magnitudes of $6 \mathrm{mV} / \mathrm{m}$. Such magnitudes are 60 times larger than quiettime values. Furthermore, Wygant et al. [1998] also noted that strong impulsive electric fields with amplitudes of up to $20 \mathrm{mV} / \mathrm{m}$ (i.e., more than three times the largest convection electric field) were observed during magnetic field dipolarizations in the inner magnetosphere, i.e., during substorm expansions or intensifications. Consequently, substorm-induced electric fields "compete" with the convection electric field in particle acceleration during storm development: they are episodic, but on the other side they are much stronger.

[61] In summary, to account consistently for a vast amount of complicated observations in space and on the Earth's surface in terms of the storm/substorm relationship, the following points should be considered:

[62] 1. A major space storm occurs when the interplanetary magnetic field (IMF) has a sustained (more than 3 hours) of intense (more than $10 \mathrm{nT}$ ) southward component [Gonzalez and Tsurutani, 1987].

[63] 2. No storms have been observed during which intense substorms did not occur. This implies that storms and substorms have a common cause, yet does not necessarily mean that one results in the other.

[64] 3. Geomagnetic activity at high latitudes is always very high during a magnetic storm. When substorm activity is of a lesser magnitude, however, a magnetic storm may or may not be underway, depending on some yet undefined conditions. 
[65] 4. Some large substorms are associated with the significant main phase, while other equally large substorms have little effect. Some storms recover very quickly as soon as the IMF turns northward, while others take a long time to recover.

[66] It seems likely that space storms and magnetospheric substorms may occur as rather independent processes. The simple occurrence of substorms does not seem to be a sufficient condition for a magnetic storm [Kamide, 1992]. In this view the reason substorms occur during storms is that the IMF condition for substorms is included in the IMF condition for storms. In addition the question of the storm/ substorm relationship cannot be addressed properly without considering that not all enhancements of the $A L$ index are substorms. A further complication in understanding quantitatively the storm/substorm relationship lies in the existence of the quasi-steady state of the magnetosphere [Sergeev et al., 1996]. This state can occur when the IMF is steadily southward directed.

[67] Figure 15 proposes that the quasi-steady electric field in the solar wind alone is responsible for Dst changes during space storms. In this model it is fluctuations in the electric field that generate substorms, which may or may not enhance the ring current. If we were to control the solar wind, generating purely steady southward IMF, we would be able to create a magnetic storm during which no substorm expansions occur. This situation is illustrated in Figure 15a. Actually, the interplanetary magnetic field almost always fluctuates. If the steady-state southward IMF were to happen, however, there would be no substorm expansions, although the so-called directly driven auroral electrojet would contribute to the variation of the $A E$ indices. In fact, Tsurutani et al. [2003] recently showed examples of storms where no auroral signatures of classical substorm expansions occurred. Figure $15 \mathrm{~b}$, on the other hand, illustrates the association of IMF fluctuations with substorm expansions.

[68] The scheme shown in Figure 15 conforms to a number of observations that have so far been reported, including the following:

[69] 1. When the solar wind electric field is used to predict both $D s t$ and $A L$, the prediction residuals for these two geomagnetic indices are uncorrelated [McPherron, 1997].

[70] 2. Northward turnings, or becoming less southward, of the interplanetary magnetic field have been found to trigger most of substorm expansions [e.g., Rostoker, 1983; Lyons et al., 1997]. McPherron et al. [1986] showed earlier that more than $50 \%$ of substorms are triggered by changes in the IMF.

[71] 3. Tsurutani and Gonzalez [1987] showed the existence of HILDCAAs, which stands for high-intensity, longduration, continuous $A E$ activity. When the IMF fluctuates during the recovery phase of a magnetic storm, many shortlived substorms with similar amplitudes occur continuously (corresponding to the fluctuations in the IMF) and the Dst recovery to the prestorm level is very slow, as if "delayed" by the substorms.

[72] The last point brings us to the next major topic of this paper, which is the recovery of intense storms. Storm recovery has been traditionally and implicitly linked to ring current decay, although the variations of the Dst index and
Dst

a
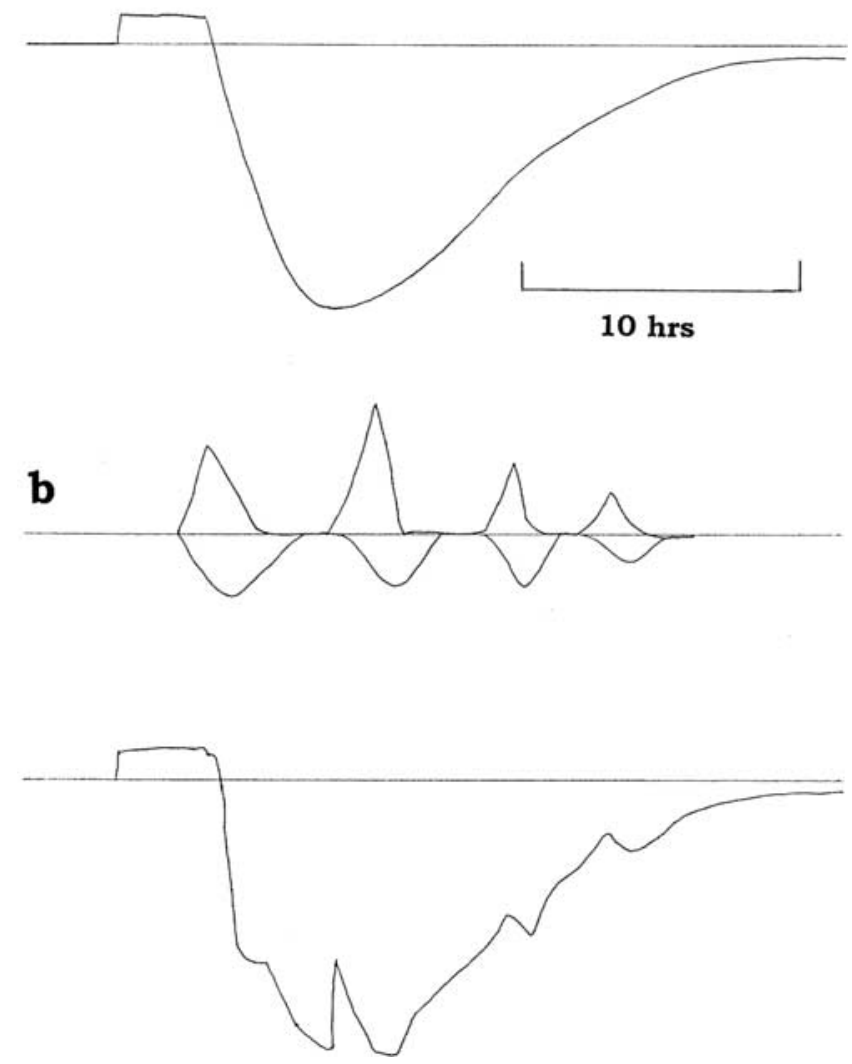

Figure 15. Schematic illustration of the proposed model for magnetic storms (in terms of Dst). The Dst variance consists of two components. The steady southward component of IMF generates an enhancement in the ring current in the magnetosphere, which can be monitored by the Dst index, whereas it is the short-term changes or fluctuations in the IMF that trigger substorm expansions.

the ring current do not necessarily represent each other accurately. The main killer candidate of the storm-time ring current has been charge exchange; the often observed feature of two-step recovery [Kamide et al., 1998a] has been interpreted as the result of a plasma composition change during the storm recovery [Hamilton et al., 1988; Daglis et al., 1999]. The reason for this is that the charge exchange lifetimes of the main ring current ion species, namely $\mathrm{H}^{+}$and $\mathrm{O}^{+}$, are radically different. In the energy range of several tens of $\mathrm{keV}(50-100 \mathrm{keV})$, where the bulk of the storm-time ring current energy is contained, the $\mathrm{O}^{+}$ lifetime can an order of magnitude shorter than that of $\mathrm{H}^{+}$. This difference is even large at higher energies. For example, at $L=5$ and a mirror latitude of $14^{\circ}$, the chargeexchange lifetime of a $100 \mathrm{keV} \mathrm{O}^{+}$ion is $\sim 46$ hours; for the same energy the lifetime of $\mathrm{H}^{+}$ions is $\sim 470$ hours. These time scales become considerably shorter in the inner ring current because the geocoronal density increases. At $L=3.5$ the respective $100 \mathrm{keV} \mathrm{O}^{+}$and $\mathrm{H}^{+}$lifetimes are 11 and 110 hours. In contrast in the lower energy range $\mathrm{O}^{+}$has a much longer lifetime than $\mathrm{H}^{+}$: at $L=5$ the $10 \mathrm{keV} \mathrm{O}^{+}$and $\mathrm{H}^{+}$ 
lifetimes are $\sim 56$ hours and $\sim 17$ hours, respectively. At $L=$ 3.5 the lifetimes become 28 and 5.5 hours, respectively. The implications of these differences are very important. A large (not to mention a dominant) $\mathrm{O}^{+}$component will induce: (1) a rapid initial decay after the storm maximum, due to the rapid loss of high-energy $\mathrm{O}^{+}$and (2) a decrease of the decay rate during the recovery phase, due to the relatively long lifetimes of low-energy $\mathrm{O}^{+}$.

[73] It is obvious that variations in the relative abundance of the two main ion species $\mathrm{H}^{+}$and $\mathrm{O}^{+}$can regulate the decay rate of the storm-time ring current and should therefore be taken into account in any comprehensive modeling study. However, several case studies and simulations indicated limitations of charge-exchange losses as the main cause of ring current decay during storm recovery [e.g., Takahashi et al., 1990]. In particular, the two-phase recovery has not been reproducible by charge-exchange losses alone [e.g., Fok et al., 1995; Liemohn et al., 1999; Kozyra et al., 2002]. Alternative mechanisms for ring current losses are wave-particle interactions, precipitation, and convective drift escape through the dayside magnetopause. The relative contributions of these processes seem to be different from case to case.

[74] Liemohn et al. [2001] suggested that the two-phase recovery of intense storms is due to the transition between fast time-scale "flow-out" losses (associated with open drift paths) and much slower "charge-exchange" losses (associated with closed drift paths) rather than the transition between fast " $\mathrm{O}^{+}$" and slower " $\mathrm{H}^{+}$" charge-exchange losses (associated with a trapped ring current). [Liemohn et al., 2001] attributed the dramatic loss of $\mathrm{O}^{+}$compared with $\mathrm{H}^{+}$, typically observed in the early recovery phase of major storms to composition changes in the inner plasma sheet rather than to composition-dependent decay mechanisms. This increasingly oxygen-poor plasma is convected into the inner magnetosphere along open drift paths which are being converted to closed drift paths as the convection electric field weakens (magnetic activity subsides).

[75] It is seen that the rapid time scales associated with "flow-out" losses during the main and early recovery phase are dependent on the strength of magnetospheric convection. With a fixed plasma sheet density and unchanging convection pattern during the minimum in $D s t^{*}$, the efolding loss time scale is roughly the time for $70 \%$ of the ion energy in the partial ring current to convect from the nightside plasma sheet to the dayside magnetopause. If we approximate this as the time for ions around the typical peak ring current energies (at $L \sim 3$ ) to convect from the dusk region out the dayside magnetopause, the time scale should be 2-9 hours. This is consistent with the 3-5 hour time scales for loss obtained from the simulations of the main phase. Independently [O'Brien and McPherron, 2000] found that decay time-scales in the $D s t^{*}$ index are correlated with solar wind $v B_{s}\left(=E_{y}\right)$. These results are consistent since the solar wind $E_{y}$ is closely related to the convection $E_{y}$ in the magnetosphere through reconnection at the dayside magnetopause.

[76] However, the particular storm in June 1991 exhibited a dominant role of charge exchange during the initial fast recovery. This is presumably due to the large $\mathrm{O}^{+}$abundance in the June 1991 storm-time ring current, and the relatively short charge-exchange lifetime of $\mathrm{O}^{+}$as discussed above.
[77] The complex interplay between flow-out and charge exchange losses during the June 1991 storm is presumably the combined effect of the ring current composition and the fluctuations in the interplanetary magnetic field. The IMF fluctuations influence the convection electric field and consequently the convection pattern of the incoming ions and their loss through the dayside magnetopause, while the $\mathrm{O}^{+}$dominated ring current favors rapid decay through charge exchange. This is evident in the early, fast recovery phases of the storm and even more in the late recovery, when charge-exchange losses become much larger than flow-out losses (factor of 5 to 10). In the September 1998 storm, which did not have a large $\mathrm{O}^{+}$component, the initial recovery phase was dominated by convective flow-out losses.

[78] In conclusion our two-storm investigation clearly shows the increasing importance of charge-exchange loss in the main and early recovery phase for storms with a large $\mathrm{O}^{+}$component in the ring current. Since solar maximum storms tend to be more enriched in $\mathrm{O}^{+}$than solar minimum storms, these results imply a solar cycle influence on main and early recovery phase time scales for a fixed storm size.

[79] The energy distribution within the magnetosphere is very different for these two storm events even though the minimum $D s t^{*}$ is similar. During the June 1991 storm the ring current dissipated the major portion of the storm energy, whereas in the September 1998 event the Joule heating was the largest energy sink. Understanding the factors that control the apportionment of magnetic storm energy within the magnetosphere is central to understanding the geoeffectiveness of solar wind structures. Better techniques for estimating the energy budget are needed to eliminate uncertainties. In addition, energy budgets for a large variety of storms during all phases of the solar cycle are needed to understand how the energy is apportioned within the magnetosphere as storm parameters change.

[80] The prediction of storms, particularly large storms, is one of the challenges of space storm research and space weather initiatives. The recognition that the solar wind induced electric field is the main driver of space storms [Gonzalez and Tsurutani, 1987] has made it possible to predict them accurately. In the earliest model [Burton et al., 1975], storms are considered directly driven by the solar wind, in particular the flow induced electric field. Such models predict the Dst from the solar wind induced electric field well but the strength of the coupling to the solar wind varies with the activity level, thus require updating its value externally. Nonlinear dynamical techniques [e.g., Vassiliadis et al., 1995; Valdivia et al., 1996] have the ability to update the model parameters using the previous data of the storms and the solar wind variables. This approach has given predictions of the Dst with errors of 4-6 nT for 1 hour predictions [Valdivia et al., 1996]. Improved predictions are obtained by using a spatio-temporal model to predict the $\mathrm{H}$ components at the midlatitude stations and then computing the Dst [Valdivia et al., 1999]. Most of these studies use the solar wind $v B_{z}$ as the input that drives the storm and improved predictions are expected when other relevant solar wind variables are included as the input. In the case when both $v B_{z}$ and $v B_{y}$ are taken as the inputs, the prediction of the peak of the storm significantly improves [Sharma, 1996]. Other variables such as the solar wind density and 
dynamic pressure, as well as the plasma sheet density, play important roles in storm evolution and including these as inputs in the prediction models is expected to yield better predictions.

[81] Acknowledgments. This work was partially supported by the General Secretariat of Research and Technology of the Greek Ministry of Development. The research at the University of Maryland is supported by NSF grants ATM-9713479 and ATM-0001676. Portions of this work were performed at the Jet Propulsion Laboratory, California Institute of Technology under contract with NASA. The Dst index used in this work is courtesy of the World Data Center, Kyoto, and STEL, Nagoya University, Japan.

[82] Shadia Rifai Habbal thanks Donald G. Mitchell and George Siscoe for their assistance in evaluating this paper.

\section{References}

Abarbanel, H. D., R. Brown, J. J. Sidorovich, and L. S. Tsimring, The analysis of observed chaotic data in physical systems, Rev. Mod. Phys., 65, 1331-1392, 1993.

Akasofu, S.-I., Polar and Magnetospheric Substorms, D. Reidel, Norwell, Mass., 1968.

Akasofu, S.-I., Energy coupling between the solar wind and the magnetosphere, Space Sci. Rev., 28, 121-190, 1981

Akasofu, S.-I., and S. Chapman, The ring current, geomagnetic disturbance, and the Van Allen radiation belts, J. Geophys. Res., 66, 1321-1350, 1961.

Akasofu, S.-I., B. H. Ahn, Y. Kamide, and J. H. Allen, A note on the accuracy of the auroral electrojet indices, J. Geophys. Res., 88, 57695772, 1983.

Baker, D. N., T. I. Pulkkinen, V. Angelopoulos, W. Baumjohann, and R. L. McPherron, Neutral line model of substorms: Past results and present view, J. Geophys. Res., 101, 12,975-13,010, 1996.

Belian, R. D., G. R. Gisler, T. Cayton, and R. Christensen, High-Z energetic particles at geosynchronous orbit during the great solar proton event series of October 1989, J. Geophys. Res., 97, 16,897, 1992.

Borovsky, J. E., M. F. Thomsen, G. D. Reeves, M. W. Liemohn, J. U. Kozyra, C. R. Clauer, and H. J. Singer, Global sawtooth oscillations of the magnetosphere during large storms, Eos Trans. $A G U, 82(47)$, Fall Meet. Suppl., Abstract SM42D-08, 2001.

Burch, J. L., Preconditions for the triggering of polar magnetic substorms by storm sudden commencements, J. Geophys. Res., 77, 5629-5632, 1972.

Burton, R. K., R. L. McPherron, and C. T. Russell, An empirical relationship between interplanetary conditions and Dst, J. Geophys. Res., 80, 4204-4214, 1975

Campbell, W. H., Geomagnetic storms, the Dst ring-current myth and lognormal distributions, J. Atmos. Terr. Phys., 58, 1171-1187, 1996.

Casdagli, M., A dynamical system approach to modeling input-output systems, in Nonlinear Modeling and Forecasting, SFI Studies in the Sciences of Complexity, vol. XII, edited by M. Casdagli and S. Eubank, pp. 265-282, Addison-Wesley, New York, 1992.

Chapman, S., Earth storms: Retrospect and prospect, J. Phys. Soc. Jpn., 17, Suppl. A-I, 6-16, 1962.

Chen, M. W., L. Lyons, and M. Shultz, Simulations of phase space distributions of storm time proton ring current, J. Geophys. Res., 99, 5745 5759, 1994

Clauer, C. R., and R. L. McPherron, Mapping the local time-universal time development of magne tospheric substorms using mid-latitude magnetic observations, J. Geophys. Res., 79, 2811-2820, 1974

Daglis, I. A., The role of magnetosphere-ionosphere coupling in magnetic storm dynamics, in Magnetic Storms, Geophys. Monogr. Ser., vol. 98, edited by B. T. Tsurutani et al., pp. 107-116, AGU, Washington, D. C., 1997a.

Daglis, I. A., Terrestrial agents in the realm of space storms: Missions study oxygen ions, Eos Trans. AGU, 24, 245-251, 1997b.

Daglis, I. A., Space storms, ring current and space-atmosphere coupling, in Space Storms and Space Weather Hazards, edited by I. A. Daglis, pp. 1-42, Kluwer Acad., Norwell, Mass., 2001.

Daglis, I. A., and W. I. Axford, Fast ionospheric response to enhanced activity in geospace: Ion feeding of the inner magnetotail, J. Geophys. Res., 101, 5047-5065, 1996.

Daglis, I. A., and Y. Kamide, The role of substorms in storm-time particle acceleration, in Storm-Substorm Relation, Geophys. Monogr. Ser., edited by S. Sharma et al., AGU, Washington, D. C., in press, 2003.

Daglis, I. A., and S. Livi, Merits for substorm research from imaging of charge-exchange neutral atoms, Ann. Geophys., 13, 505-516, 1995.

Daglis, I. A., Y. Kamide, G. Kasotakis, C. Mouikis, B. Wilken, E. T. Sarris and R. Nakamura, Ion composition in the inner magnetosphere: Its im- portance and its potential role as a discriminator between storm-time and non-storm-time substorms, in Fourth International Conference on Substorms (ICS-4), edited by S. Kokubun and Y. Kamide, pp. 767-772, Terra Sci., Tokyo, 1998.

Daglis, I. A., R. M. Thorne, W. Baumjohann, and S. Orsini, The terrestrial ring current: Origin, formation, and decay, Rev. Geophys., 37, 407-438, 1999.

Daglis, I. A., Y. Kamide, C. Mouikis, G. D. Reeves, E. T. Sarris, K. Shiokawa, and B. Wilken, "Fine structure" of the storm-substorm relationship, Adv. Space Res., 25(12), 2369-2372, 2000.

Delcourt, D. C., Particle acceleration by inductive electric fields in the inner magnetosphere, J. Atmos. Sol. Terr. Phys., 64, 551-559, 2002.

Edwards, J., A. S. Sharma, M. I. Sitnov, K. Papadopoulos, and Y. Kamide, Dynamical time scales of the magnetosphere: Comparisons using geomagnetic indices and magnetometer data, Eos Trans. $A G U, 81$, Spring Meet. Suppl., S404, 2000.

Elphinstone, R. D., What is a global auroral substorm?, Rev. Geophys., 34, $169-232,1996$.

Fok, M.-C., T. E. Moore, J. U. Kozyra, G. C. Ho, and D. C. Hamilton, Three-dimensional ring current decay model, J. Geophys. Res., 100, 9619-9632, 1995.

Fok, M.-C., T. E. Moore, and M. E. Greenspan, Ring current development during storm main phase, J. Geophys. Res., 101, 15,311-15,322, 1996.

Fok, M.-C., T. E. Moore, and D. C. Delcourt, Modeling of inner plasma sheet and ring current during substorms, J. Geophys. Res., 104, 14,557$14,569,1999$.

Fraser, A. M., and H. L. Swinney, Independent coordinates for strange attractors from mutual information, Phys. Rev. A, 33, 1134, 1986.

Gonzalez, W. D., and B. T. Tsurutani, Criteria of interplanetary parameters causing intense magnetic storms (Dst $<-100 \mathrm{nT})$, Planet. Space Sci., 35 , $1101-1109,1987$

Gonzalez, W. D., J. A. Joselyn, Y. Kamide, H. W. Kroehl, G. Rostoker, B. T. Tsurutani, and V. M. Vasyliunas, What is a geomagnetic storm?, J. Geophys. Res., 99, 5771-5792, 1994

Hamilton, D. C., G. Gloeckler, F. M. Ipavich, W. Stüdemann, B. Wilken, and G. Kremser, Ring current development during the great geomagnetic storm of February 1986, J. Geophys. Res., 93, 14,343-14,355, 1988.

Iyemori, T., and D. R. K. Rao, Decay of the Dst field of geomagnetic disturbance after substorm onset and its implication to storm-substorm relation, Ann. Geophys., 14, 608-618, 1996.

Jordanova, V. K., J. U. Kozyra, G. Khazanov, A. F. Nagy, C. E. Rasmussen, and M.-C. Fok, A bounce-averaged kinetic model of the ring current ion population, Geophys. Res. Lett., 21, 2785-2788, 1994.

Jordanova, V. K., L. M. Kistler, J. U. Kozyra, G. V. Khazanov, and A. F. Nagy, Collisional losses of ring current ions, J. Geophys. Res., 101, $111-$ $126,1996$.

Kamide, Y., Is substorm occurrence a necessary condition for a magnetic storm?, J. Geomagn. Geoelectr., 44, 109-117, 1992

Kamide, Y., and S.-I. Akasofu, Notes on the auroral electrojet indices, Rev. Geophys., 21, 1647-1656, 1983.

Kamide, Y., and J. H. Allen, Some outstanding problems of the storm/ substorm relationship, in Solar-Terrestrial Predictions, vol. V, edited by G. Heckman et al., pp. 207-216, Comm. Res. Lab., Tokyo, Japan, 1997. Kamide, Y., N. Yokoyama, W. D. Gonzalez, B. T. Tsurutani, I. A. Daglis, A. Brekke, and S. Masuda, Two-step development of geomagnetic storms, J. Geophys. Res., 103, 6917-6921, 1998 a.

Kamide, Y., et al., Current understanding of magnetic storms: Storm/substorm relationships, J. Geophys. Res., 103, 17,705-17,728, 1998b.

Kokubun, S., R. L. McPherron, and C. T. Russell, Triggering of substorms by solar wind discontinuities, J. Geophys. Res., 82, 74, 1977.

Korth, A., R. H. W. Friedel, M. G. Henderson, F. Frutos-Alfaro, and C. G. Mouikis, $\mathrm{O}^{+}$transport into the ring current: Storm versus substorm, in Storm-Substorm Relation, Geophys. Monogr. Ser, edited by S. Sharma et al., AGU, Washington, D. C., in press, 2003.

Kozyra, J. U., V. K. Jordanova, R. B. Horne, and R. M. Thorne, Modeling of the contribution of electromagnetic ion cyclotron (EMIC) waves to stormtime ring current erosion, in Magnetic Storms, Geophys. Monogr. Ser. vol. 98, edited by B. T. Tsurutani et al., pp. 187-202, AGU, Washington, D. C., 1997.

Kozyra, J. U., M. W. Liemohn, C. R. Clauer, A. J. Ridley, M. F. Thomsen, J. E. Borovsky, J. L. Roeder, V. K. Jordanova, and W. D. Gonzalez, Multistep $D_{s t}$ development and ring current composition changes during the 4-6 June 1991 magnetic storm, J. Geophys. Res, 107(A8), 1224, doi:10.1029/2001JA000023, 2002.

Lennartsson, W., Energetic (0.1- to $16-\mathrm{keV} / e)$ magnetospheric ion composition at different levels of solar F10.7, J. Geophys. Res., 94, 3600-3610, 1989.

Liemohn, M. W., J. U. Kozyra, V. K. Jordanova, G. V. Khazanov, M. F. Thomsen, and T. E. Cayton, Analysis of early phase ring current recovery mechanisms during geomagnetic storms, Geophys. Res. Lett., 26, 28452848, 1999. 
Liemohn, M. W., J. U. Kozyra, M. F. Thomsen, J. L. Roeder, G. Lu, J. E. Borovsky, and T. E. Cayton, Dominant role of the asymmetric ring current in producing the stormtime Dst*, J. Geophys. Res., 106, 10,88310,904, 2001.

Lyons, L. R., G. T. Blanchard, J. C. Samson, R. P. Lepping, T. Yamamoto, and T. Moretto, Coordinated observations demonstrating external substorm triggering, J. Geophys. Res., 102, 27,039, 1997.

McComas, D. J., S. J. Bame, B. L. Barraclough, J. R. Donart, R. C. Elphic, J. T. Gosling, M. B. Moldwin, K. R. Moore, and M. F. Thomsen, Magnetospheric plasma analyzer: Initial three-spacecraft observations from geosynchronous orbit, J. Geophys. Res., 98, 13,453, 1993.

McIlwain, C. E., A Kp-dependent equatorial electric field model, $A d v$. Space Res., 6, 187, 1986.

McPherron, R. L., The role of substorms in the generation of magnetic storms, in Magnetic Storms, Geophys. Monogr. Ser., vol. 98, edited by B. T. Tsurutani et al., pp. 131-147, AGU, Washington, D. C., 1997.

McPherron, R. L., T. Terasawa, and A. Nishida, Solar wind triggering of substorm expansion onset, J. Geomagn. Geoelectr., 38, 1089-1108, 1986.

Mitchell, D. G., K. C. Hsieh, C. C. Curtis, D. C. Hamilton, H. D. Voss, E. C. Roelof, and P. C:son-Brandt, Imaging two geomagnetic storms in energetic neutral atoms, Geophys. Res. Lett., 28, 1151-1154, 2001.

Monreal-MacMahon, R., and W. D. Gonzalez, Energetics during the main phase of geomagnetic superstorms, J. Geophys. Res., 102, 14,19914,207, 1997.

Nakamura, R., S. Kokubun, T. Mukai, and T. Yamamoto, Changes in the distant tail configuration during geomagnetic storms, J. Geophys. Res., 102, 9587, 1997.

O'Brien, T. P., and R. L. McPherron, An empirical phase space analysis of ring current dynamics: Solar wind control of injection and decay, J. Geophys. Res., 105, 7707-7719, 2000.

Pollock, C. J., et al., Initial Medium Energy Neutral Atom (MENA) images of Earth's magnetosphere during substorm and storm-time, Geophys. Res. Lett., 28, 1147-1150, 2001.

Price, C. P., and D. Prichard, The nonlinear response of the magnetosphere: 30 October 1978, Geophys. Res. Lett., 20, 771-774, 1993.

Rairden, R. L., L. A. Frank, and J. D. Craven, Geocoronal imaging with Dynamics Explorer, J. Geophys. Res., 91, 13,613-13,630, 1986.

Rasmussen, C. E., S. M. Guiter, and S. G. Thomas, Two-dimensional model of the plasmasphere: Refilling time constants, Planet. Space Sci., 41, 35 42, 1993.

Richmond, A. D., and Y. Kamide, Mapping electrodynamic features of the high-latitude ionosphere from localized observations: Technique, J. Geophys. Res., 93, 5741-5759, 1988.

Roelof, E. C., Remote sensing of the ring current using energetic neutral atoms, Adv. Space Res., 9, 195-203, 1989.

Rostoker, G., Triggering of expansive phase intensifications of magnetospheric substorms by northward turnings of the interplanetary magnetic fields, J. Geophys. Res., 88, 6981, 1983.

Sergeev, V. A., R. J. Pellinen, and T. I. Pulkkinen, Steady magnetospheric convection and magnetic activity, Space Sci. Rev., 75, 551, 1996.

Sharma, A. S., Assessing the magnetosphere's nonlinear behaviour: Its dimension is low, its predictability is high, Rev. Geophys., 35, 645, 1995.

Sharma, A. S., Nonlinear dynamics of the magnetosphere and space weather, in Third International Conference on Substorms (ICS-3), ESA SP-389, edited by E. J. Rolfe and B. Kaldeich, pp. 645-650, Eur. Space Agency, Paris, 1996.

Sheldon, R. B., and D. C. Hamilton, Ion transport and loss in the Earth's quiet ring current: 1. Data and standard model, J. Geophys. Res., 98, $13,491-13,508,1993$.

Takahashi, S., T. Iyemori, and M. Takeda, A simulation of the storm-time ring current, Planet. Space Sci., 38, 1133-1141, 1990.

Thorne, R. M., and R. B. Horne, Energy transfer between energetic ring current $\mathrm{H}^{+}$and $\mathrm{O}^{+}$by electromagnetic ion cyclotron waves, J. Geophys. Res., 99, 17,275-17,282, 1994.
Tinsley, B. A., and S.-I. Akasofu, A note on the lifetime of the ring current particles, Planet. Space Sci., 30, 733-740, 1982.

Tsurutani, B. T., The interplanetary causes of magnetic storms, substorms and geomagnetic quiet, in Space Storms and Space Weather Hazards, edited by I. A. Daglis, pp. 103-130, Kluwer Acad., Norwell, Mass., 2001.

Tsurutani, B. T., and W. D. Gonzalez, The cause of high intensity longduration continuous AE activity (HILDCAAs): Interplanetary Alfven wave trains, Planet. Space Sci., 35, 405, 1987.

Tsurutani, B. T., X.-Y. Zhou, and W. D. Gonzalez, A lack of substorm expansion phases during magnetic storms induced by magnetic clouds, in Storm-Substorm Relation, Geophys. Monogr. Ser., edited by S. Sharma et al., AGU, Washington, D. C., in press, 2003.

Valdivia, J. A., A. S. Sharma, and K. Papadopoulos, Prediction of magnetic storms by nonlinear models, Geophys. Res. Lett., 23, 2899-2902, 1996.

Valdivia, J. A., D. Vassiliadis, A. J. Klimas, A. S. Sharma, and K. Papadopoulos, Spatio-temporal activity of magnetic storms, J. Geophys. Res., 104, 12,239, 1999.

Vassiliadis, D., and I. A. Daglis, Developing diagnostics for input-output systems: The effects of certain linear and nonlinear filters on the correlation integral, Nonlin. Proc. Geophys., 1, 136-144, 1994.

Vassiliadis, D., A. S. Sharma, T. E. Eastman, and K. Papadopoulos, Lowdimensional chaos in magnetospheric activity from $A E$ time series, Geophys. Res. Lett., 17, 1841-1844, 1990.

Vassiliadis, D., A. J. Klimas, D. N. Baker, and D. A. Roberts, A description of the solar wind-magnetosphere coupling based on nonlinear filters, J. Geophys. Res., 100, 3495-3512, 1995.

Vassiliadis, D., A. J. Klimas, J. A. Valdivia, and D. N. Baker, The Dst geomagnetic response as a function of storm phase and amplitude and the solar wind electric field, J. Geophys. Res., 104, 24,957-24,976, 1999.

von Humboldt, A., Die vollständigste aller bisherigen Beobachtungen über den Einfluss des Nordlichts auf die Magnetnadel, Ann. Phys., 29, 425429, 1808.

Williams, D. J., E. C. Roelof, and D. G. Mitchell, Global magnetospheric imaging, Rev. Geophys., 30, 183-208, 1992.

Wygant, J., D. Rowland, H. J. Singer, M. Temerin, F. Mozer, and M. K. Hudson, Experimental evidence on the role of the large spatial electric field in creating the ring current, J. Geophys. Res., 103, 29,527-29,544, 1998.

Young, D. T., H. Balsiger, and J. Geiss, Correlations of magnetospheric ion composition with geomagnetic and solar activity, J. Geophys. Res., 87, 9077-9096, 1982.

Zaitzev, A. N., and R. Boström, On methods of graphical displaying of polar magnetic disturbances, Planet. Space Sci., 19, 643-649, 1971

I. A. Daglis, Institute for Space Applications and Remote Sensing, National Observatory of Athens, Penteli, 15236 Athens, Greece. (daglis@ space.noa.gr)

W. D. Gonzalez, Instituto de Pesquisas Espaciais, CP 515, 12201-970 Sao Jose dos Campos, Brazil. (gonzalez@dge.inpe.br)

Y. Kamide, Solar-Terrestrial Environment Laboratory, Nagoya University, 442 Toyokawa, Japan. (kamide@stelab.nagoya-u.ac.jp)

J. U. Kozyra and M. W. Liemohn, Space Physics Research Laboratory, 2455 Hayward St., University of Michigan, Ann Arbor, MI 48109-2143, USA. (jukozyra@umich.edu; liemohn@umich.edu)

G. Lu, High Altitude Observatory, NCAR, Boulder, CO 80307-3000, USA. (ganglu@hao.ucar.edu)

A. S. Sharma, University of Maryland, College Park, MD 20782, USA. (ssh@astro.umd.edu)

B. T. Tsurutani, Jet Propulsion Laboratory, California Institute of Technology, Pasadena, CA 91109, USA. (btsurutani@jplsp.jpl.nasa.gov)

D. Vassiliadis, Universities Space Research Association at NASA Goddard Space Flight Center, Greenbelt, MD 20771, USA. (vassi@electra. gsfc.nasa.gov) 